\title{
Scanning Tunneling Microscopy, Voltammetry, and X-ray Photoelectron Spectroscopy Study of the Early Stages of Electrochemical Faceting of Gold (111) in Aqueous Sulfuric and Perchloric Acid
}

\author{
Felipe J. Rodríguez Nieto, Gustavo Andreasen, María E. Martins, Federico Castez, \\ Roberto C. Salvarezza, and Alejandro J. Arvia* \\ Instituto de Investigaciones Fisicoquímicas Teóricas y Aplicadas (INIFTA, Universidad Nacional de La \\ Plata-Consejo Nacional de Investigaciones Científicas y Técnicas) Sucursal 4, Casilla de Correo 16, \\ (1900) La Plata, Argentina
}

Received: May 16, 2003; In Final Form: July 28, 2003

\begin{abstract}
The mechanism of the early stages of the electrochemical faceting of $\mathrm{Au}(111)$ in $1 \mathrm{M}$ aqueous sulfuric and $1 \mathrm{M}$ aqueous perchloric acid was investigated, at room temperature, combining voltammetry, scanning tunneling microscopy, and X-ray photoelectronic spectroscopy data. The analysis of the first electro-oxidation scan indicates that the formation of $\mathrm{OH}$ - and $\mathrm{O}$-electroadsorbed species is accompanied by $2 \mathrm{D}$ clustering. Subsequent electro-oxidation scans involve the participation of deeper $\mathrm{Au}(111)$ atom layers. Clustering effects are favored by the presence of specifically adsorbed anions. After the electro-oxidation scan, the subsequent fast electroreduction of $\mathrm{OH}$ - and $\mathrm{O}$-adsorbates initially produces spinoidal patterns that disappear by clustering, 2D metal island growth at different lattice levels, coalescence of islands, and 2D Ostwald ripening. This complex mechanism involves the participation of cooperative surface phenomena. Repetitive electro-oxidation/ electroreduction potential cycling assists the formation of small 3D crystallites leading to Au(111) surface faceting.
\end{abstract}

\section{Introduction}

Faceting has been defined as the break-up of a surface of some arbitrary macroscopic orientation into a "hill and valley" structure that exposes surfaces of different orientation. ${ }^{1}$ Faceting can be produced perturbing the solid/environment interfacial region by thermal treatment, ${ }^{2,3}$ potential-induced surface reconstruction, ${ }^{4}$ adsorbate formation, ${ }^{5}$ or external pressure. ${ }^{6}$ According to the perturbation routine, different interactions at the surface level assist the development of faceting. In many situations a lowering of the surface free energy has been considered as the driving force for faceting, as occurs in the thermodynamic separation of different phases, where each phase would be related to a surface with a particular orientation. Then, the phase diagram relevant for faceting are equilibrium crystal shapes. However, faceting requires a relatively large contribution of mass transport at the surface. Consequently, faceting often occurs irreversibly when the environment of the surface is changed, for instance, in the presence of impurities.

Generally, faceting is easily observable when facets have reached the micrometer-scale, although at this length scale it is difficult to describe the early stages of the process at the molecular level. This situation, however, has changed from the use of low-energy electron diffraction techniques and the development of surface scanning probe microscopies that permit the real space imaging of the surface morphology during faceting.

The electrochemical faceting of both polycrystalline and single-crystal metal electrodes in aqueous acids was described several decades ago as a procedure to generate facets of definite and predeterminable orientation, as well as the crystallographic

\footnotetext{
* Corresponding author. E-mail: ajarvia@infita.unlp.edu.ar.
}

direction in which these facets 1 lie. ${ }^{7-10}$ This can be easily achieved by an appropriate choice of the electrochemical parameters. In this procedure, as the initial crystal shape is far from equilibrium, the surface free energy of the crystal is lowered by increasing the net surface area to expose a weakly disordered structure of facets present under equilibrium conditions. ${ }^{11,12}$

Changes in the topography of $\mathrm{Au}(111)$ single-crystal sphere electrodes prepared by the method reported in refs 13,14 and immersed in aqueous acid solution by electrochemical faceting were reported about a decade ago. ${ }^{10,15}$ This process depends on the composition of the electrolyte solution, as expected, because it occurs in the potential range where gold-anion adsorption interactions play a key role in determining the behavior of the electrochemical interface. ${ }^{16-21}$ It is well established that ionic species with strongly bound solvation shells, such as perchlorate ion, interact with the metal surface by electrostatic forces so the excess concentration of the ionic species at a given potential becomes independent of its chemical nature. Conversely, weakly solvated ions form a chemical bond with the metal surface by partly stripping their solvation shell. These ions, such as sulfate and acid sulfate ions, are specifically adsorbed on gold. ${ }^{17,22,23}$

On the other hand, several atomic STM resolution and AFM studies of differently prepared $\mathrm{Au}(111)$ single-crystal electrode surfaces in aqueous acid have shown that under potential cycling a number of modifications can be observed. ${ }^{16,24-30}$ Thus, the $\mathrm{Au}(111)$ surface becomes rough and in part dissolves in solution accompanying a single oxidation and reduction cycle. Experiments made with $\mathrm{Au}(111)$ surfaces that have been prepared by vacuum evaporation onto freshly cleaved mica also showed the formation of both islands and pits of a single gold atom depth $(0.24 \mathrm{~nm})$ after the oxidation-reduction cycling, although this 
surface morphology after a number of oxidation and reduction cycles depends on the characteristics of the applied potential routine. ${ }^{28,30} \mathrm{STM}$ results have also shown that the gold oxide layer is rough and amorphous consisting of small hillocks $0.10-$ $0.25 \mathrm{~nm}$ in height. ${ }^{30}$ Crystalline gold oxides are seldom referred to in the literature. They are limited exclusively to those obtained by hydrothermal synthesis. ${ }^{31,32}$

The dynamics of nanoscale island growth, stability, and dissolution accompanying the potential-induced surface reconstruction of $\mathrm{Au}(111)$ in $0.1 \mathrm{M}$ aqueous perchloric acid has been studied more extensively by potential pulse perturbed timeresolved STM. ${ }^{33}$ These islands are metastable and dissolve with time, and small islands decay faster than larger islands. Evidence of electrochemical Ostwald ripening has been obtained, as even under metastable conditions large islands frequently grow before ultimately decaying. Perimeter detachment as a rate-determining step provides a qualitative explanation for the observed decay dynamics.

Despite the number of studies made on the electrochemical faceting mechanism, this is still a matter of discussion. ${ }^{34-47}$ There is neither clear understanding of the early stages of anodic formation of surface species at the levels of submonolayers and a few monolayers nor the possibility of gold atom clustering in the course of these reactions. The composition of these layers in terms of $\mathrm{OH}$ - or $\mathrm{O}$-species, and the change of the $\mathrm{OH} / \mathrm{O}$ surface concentration ratio with the applied potential and time are still far from proven. Finally, there is no quantitative evaluation about the influence of the metal-adsorbed ion interaction on the entire phenomena. These issues seem to play a key role in the electrochemical faceting of metals.

In this work attention is paid to the early stages of $\mathrm{Au}(111)$ faceting, in either $1 \mathrm{M}$ aqueous sulfuric acid or $1 \mathrm{M}$ aqueous perchloric acid, produced by single linear electro-oxidation and electroreduction scans, including a holding time at each switching potential. The anodization potential range was selected to produce adlyers from a fraction of a monolayer (ML) up to about 2.5 ML of an oxygen-containing adlayer on gold, whereas the electroreduction potential range was limited to values in which the oxygen-containing layer was electroreduced, in most cases avoiding to reach the potential of $\mathrm{Au}(111)$ surface reconstruction. Topographic changes of $\mathrm{Au}(111)$ samples were followed by in-situ scanning tunneling microscopy (STM) imaging, and the composition of the surface layer, which was determined by X-ray photoelectron spectroscopy (XPS). A reasonable correlation between XPS and voltammetric data could be established. This is a relevant starting point to advance our understanding of the mechanism of the electrochemical faceting of metals.

Results reported in this work provide new information about the mechanism at the early stages of $\mathrm{Au}(111)$ electrochemical faceting. It starts with the formation of $\mathrm{OH}$ - and O-electroadsorbed species from the electro-oxidation of water, and the simultaneous desorption of anions, and clustering of gold atoms forming 2D islands covered by $\mathrm{OH}-$ and O-adsorbates. Subsequently, the initial stages of the electroreduction process involve a nucleation and 2D growth of gold clusters followed by a spinodal topography that disappear by clustering, coalescence of islands, and Ostwald ripening 2D processes. The dynamics of the electroreduced $\mathrm{Au}(111)$ topography at a $100 \mathrm{~nm}$ scale is associated with a defined size distribution of clusters in which the maximum cluster radius increases with time. This complex mechanism, in which surface diffusion of adsorbates and gold adatoms, influenced by cooperative phenomena, play a relevant role, offers a reasonable explanation for the electrochemical faceting of $\mathrm{Au}(111)$ in aqueous acids.

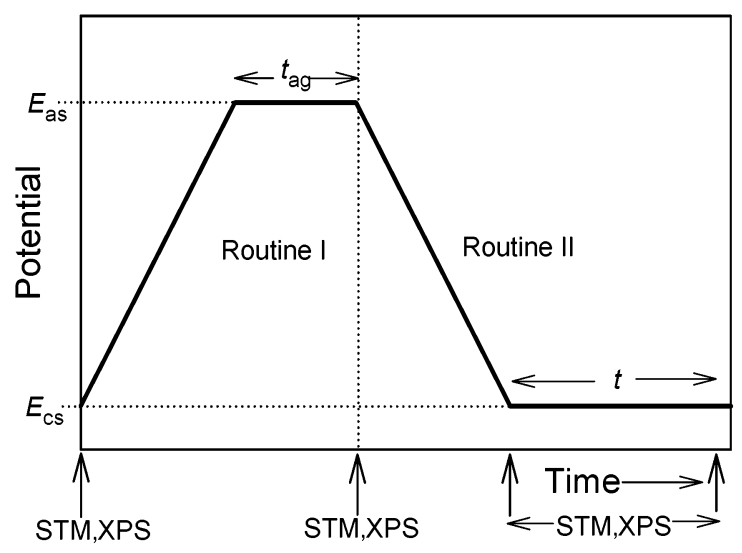

Figure 1. Scheme of potential routines I (anodization) and II (cathodization). The potential was held at the anodic switching potential $\left(E_{\text {as }}\right)$ for the time $t_{\mathrm{ag}}$ to form an anodic adlayer including its pre-selected aging at constant potential. $E_{\mathrm{cs}}$ is the cathodic switching potential. Vertical arrows indicate the time at which STM imaging and XPS analysis of samples were performed.

\section{Experimental Section}

2.1. Voltammetry. Voltammetric experiments were performed in a glass electrochemical cell. For both voltammetric runs and scanning tunneling microscopy (STM) imaging gold films evaporated on borosilicate glass (Metallhandel Schroeer $\mathrm{GmbH}$, Germany) were used. These gold films were annealed in a hydrogen flame for three minutes to obtain large $\mathrm{Au}(111)$ terraces.

For the in-situ STM measurements gold films $1 \mathrm{~cm}^{2}$ exposed area were used as working electrodes, and a $4 \mathrm{~cm}^{2}$ gold plate and a palladium/hydrogen reversible electrode, properly arranged into the cell, were utilized as counter and reference electrode, respectively. For the XPS measurements, gold films of $0.26 \mathrm{~cm}^{2}$ exposed area were employed, high-area platinum grids and a normal hydrogen electrode were used as counter and reference electrode, respectively.

Aqueous sulfuric acid (1 M) and $1 \mathrm{M}$ aqueous perchloric acid were prepared from analytical reagents and MilliQ* water, and used in all the experiments under oxygen-free nitrogen gas saturation. Runs were made at room temperature, and potentials in the text are given on the normal hydrogen electrode (NHE) scale.

The potential routine applied to the working electrode consisted of a first single voltammetric scan at $v=0.10 \mathrm{~V} / \mathrm{s}$ covering from $E_{\mathrm{i}}=0.50 \mathrm{~V}$ up to an anodic switching potential $E_{\text {as }}$ in the range $1.41 \leq E_{\text {as }} \leq 2.00 \mathrm{~V}$, including a potential holding at $E_{\mathrm{as}}$ for the time $t_{\mathrm{ag}}\left(45 \leq t_{\mathrm{ag}} \leq 750 \mathrm{~s}\right)$ to attain null current. Occasionally, a complete voltammetric cycle from 0.80 $\mathrm{V}$ to $E_{\mathrm{as}}$ and backward to the cathodic switching potential $E_{\mathrm{cs}}$ $=-0.25 \mathrm{~V}$ was made. Schemes of these potential routines (I and II) are depicted in Figure 1.

2.2. STM Imaging. STM imaging (in situ and ex situ) was performed using a Nanoscope III STM (Digital Instruments, Inc.) and commercial $\mathrm{Pt}-\mathrm{Ir}$ nanotips covered with Apiezon wax for insulation. Images were taken in the constant current mode at both $E_{\text {as }}$ (after the application of routine I) and $E_{i}$ (after the application of routine II). The scanning frequency was varied in the range $5-10 \mathrm{~Hz}$. Typical set point currents and bias voltages were 5 to $10 \mathrm{nA}$ and -0.15 to $-0.25 \mathrm{~V}$, respectively. A large area platinum counter electrode and a palladium/ hydrogen reference electrode were used in the STM electrochemical cell. Samples from conventional voltammetry were protected with a water drop before mounting for STM imaging. 
Changes in the topography of the working electrode produced by the application of either routine I or II, were followed over an area of about $100 \times 100 \mathrm{~nm}^{2}$ in which a few terraces could be distinguished.

2.3. X-ray Photoelectron Spectroscopy. The X-ray photoelectron spectra (XPS) were recorded utilizing a PHI 5600 multisystem and a $350 \mathrm{~W}$ and $15 \mathrm{kV} \mathrm{Al} \mathrm{K \alpha}$ monochromatic source. Each gold sample was systematically protected with a water drop before placing it in the vacuum chamber. Spectra were run under approximately $1 \times 10^{-9}$ Torr in the main chamber. Survey spectrum pass energy was $93.9 \mathrm{eV}$, whereas for multiplex spectra the pass energy was $5.85 \mathrm{eV}$ for Au4f, and $\mathrm{O} 1 \mathrm{~s}$ and $29.35 \mathrm{eV}$ for $\mathrm{C} 1 \mathrm{~s}$ and $\mathrm{S} 2 \mathrm{p}$. For the analysis of spectra, the background correction was made using Shirley's method, and Gaussian-Lorentzian distributions were adopted. All binding energies were corrected using the signal for adventitious $\mathrm{C} 1 \mathrm{~s}$ at $284.5 \mathrm{eV}$ as the inner standard. Quantitative spectral data were obtained utilizing the PHI software that is based on atomic sensitivity factors considering instrumental factors and the specific transition parameters of each element. Argon ion sputtering at $4 \mathrm{kV}$ was done over some blank samples to record the spectrum of very clean gold surfaces. Further details about XPS experiments are extensively described elsewhere. $^{48}$

\section{Results}

3.1. Reference Voltammetry and Au(111) Topography. A typical STM image of an unreconstructed $\mathrm{Au}(111)$ sample surface (Figure 2a,b) consists of well-defined triangular terraces of $100 \mathrm{~nm}$ average size limited by steps one or two gold atoms high. At a higher magnification, each terrace exhibits the hexagonal $\mathrm{Au}(111)$ lattice with the atom-atom nearest neighbor distance, $d_{\mathrm{Au}-\mathrm{Au}}=0.29 \mathrm{~nm}$ (Figure $2 \mathrm{c}$ ) that corresponds to ideally terminated bulk $\mathrm{Au}(111)$ with an atomic surface density of $1.35 \times 10^{15}$ atom $\mathrm{cm}^{-2}$, at $298 \mathrm{~K}$, defining the ML value at the $\mathrm{Au}(111)$ crystal face. As seen from the cross section (Figure $2 b)$ the fluctuation in flatness of these terraces is within $0.02-$ $0.03 \mathrm{~nm}$.

To adjust the values of $E_{\mathrm{cs}}$ and $E_{\mathrm{as}}$ associated with the range of the potential window in which the $\mathrm{Au}(111)$ surface reconstruction ${ }^{49-53}$ is either produced or avoided, a typical in situ single-cycle voltammogram was run at $v=0.10 \mathrm{~V} \mathrm{~s}^{-1}$ in $1 \mathrm{M}$ aqueous sulfuric acid from $E_{\mathrm{i}}=0.50 \mathrm{~V}$ to $E_{\mathrm{as}}=1.78 \mathrm{~V}$, reversed to $E_{\mathrm{cs}}=-0.25 \mathrm{~V}$, and backward to $E_{\mathrm{i}}=0.50 \mathrm{~V}$ (Figure $2 d)$. It shows the small electroadsorption charge related to sulfate ion adsorption, and $\mathrm{Au}(111)$ surface reconstruction in the range $0.50 \leq E \leq 0.90 \mathrm{~V}$, followed by the two successive processes related to the electroformation of an oxygen-containing adlayer. ${ }^{17-19,44-48}$ The electro-oxidation of water commences at $E \cong 1.3 \mathrm{~V}$ and extends up to $E_{\text {as }}=1.78 \mathrm{~V}$ defining an asymmetric, sharp anodic current peak at $1.63 \mathrm{~V}$. The corresponding anodic voltammetric charge density is $q_{\mathrm{a}}=0.454 \mathrm{mC}$ $\mathrm{cm}^{-2}$. The electroreduction of the oxygen-containing adlayer produced in the reverse scan begins at $E_{\mathrm{as}}=1.30 \mathrm{~V}$ and is characterized by a symmetric cathodic current peak at $E=1.18$ $\mathrm{V}$ comprising a cathodic charge density $q_{c}=0.443 \mathrm{mC} \mathrm{cm}^{-2}$. Besides, in the potential range $0.60 \leq E \leq 0.80 \mathrm{~V}$, the voltammogram shows a small charge associated with reversible $\mathrm{Au}(111)$ surface reconstruction and competitive sulfate ion specific adsorption. ${ }^{23,50-53}$ Finally, for $E_{\mathrm{cs}}<0 \mathrm{~V}$, the hydrogen evolution current increases exponentially as $E_{\mathrm{cs}}$ is shifted negatively. The subsequent scan from $E_{\mathrm{cs}}=-0.30 \mathrm{~V}$ upward shows a small, wide anodic current peak related to the electrooxidation of molecular hydrogen accumulated at the interface. ${ }^{7,8}$

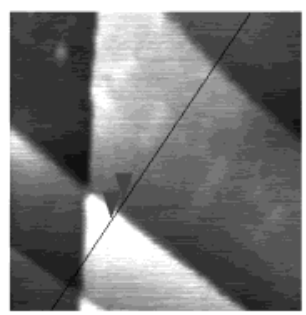

(a)

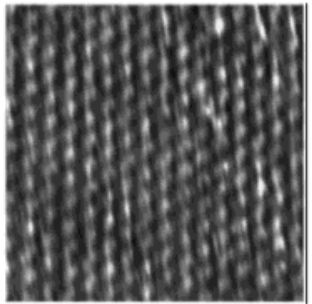

(c)

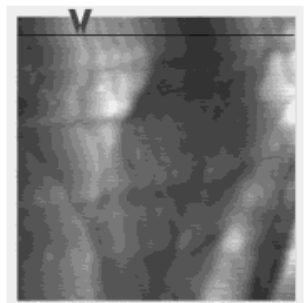

(e)

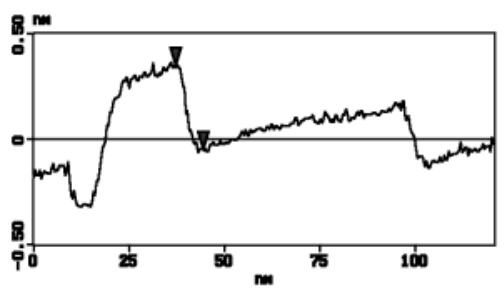

(b)

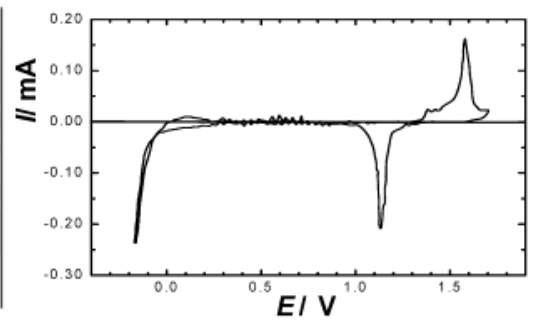

(d)

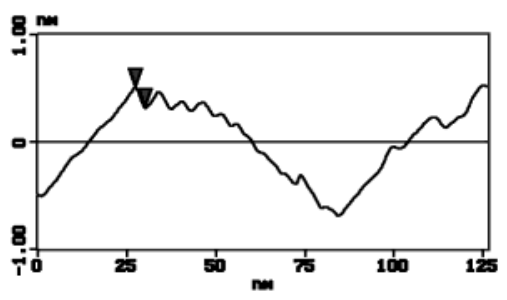

(f)
Figure 2. (a) In-situ STM image $\left(100 \times 100 \mathrm{~nm}^{2}\right)$ of the initial $\mathrm{Au}(111)$ single-crystal surface topography in $1 \mathrm{M}$ aqueous sulfuric acid. Terraces separated by well-defined steps can be observed. (b) The crossover section analysis shows flat terraces separated by steps one gold atom high, $0.24 \mathrm{~nm}$, as indicated by arrow points. The average corrugation of terraces is in the order of $0.01-0.02 \mathrm{~nm}$ as expected for a very smooth surface topography. (c) STM image $\left(2.7 \times 2.7 \mathrm{~nm}^{2}\right)$ from a terrace depicted in (a). The hexagonal lattice of gold atoms with the nearest neighbor interatomic distance $d_{\mathrm{Au}-\mathrm{Au}}=0.29 \mathrm{~nm}$ can be observed. (d) In-situ voltammogram of a $\mathrm{Au}(111)$ single-crystal sample in the STM electrochemical cell from $E_{\mathrm{i}}=0.50 \mathrm{~V}$ to $E_{\text {as }}=$ $1.78 \mathrm{~V}$, reversed to $E_{\mathrm{cs}}=-0.25 \mathrm{~V}$, and backward to $E_{\mathrm{i}}=0.50 \mathrm{~V}$, at $v=0.05 \mathrm{~V} \mathrm{~s}^{-1}$. (e) In-situ STM image $\left(100 \times 100 \mathrm{~nm}^{2}\right)$ of a $\mathrm{Au}(111)$ electrode surface at $E_{\mathrm{i}}=0.50 \mathrm{~V}$ after the application of the potential routine indicated in (d). Both reconstructed (parallel rows) and unreconstructed gold surface domains can be observed. (f) Cross-section analysis of the STM image depicted in (e). Terrace domains of different corrugations can be seen. The small corrugation of lateral size $6.3 \mathrm{~nm}$ (see arrows) corresponds to domains of the $22 \times \sqrt{ } 3$ reconstructed $\mathrm{Au}(111)$ surface.

After this treatment, the STM image of the surface sample (Figure 2e) consists of crystallites with rather diffuse borders, and domains of unreconstructed flat terraces and others with ordered "herringbone" structures. The corrugation of the surface, as derived from the cross section of the STM image, is in the range $0.09-0.17 \mathrm{~nm}$ (Figure 2f), i.e., from a fraction up to the gold atom radius, $r_{\mathrm{Au}} \cong 0.145 \mathrm{~nm}$. This figure is consistent with the flatness of the reconstructed $22 \times \sqrt{3}$ surface of $\mathrm{Au}(111)$, as well as with the separation distance of "herringbone" structures that is close to $6.3 \mathrm{~nm}$. The observation of reconstructed $\mathrm{Au}(111)$ was an indication of the gold surface cleanness.

3.2. Voltammetry. Voltammetric experiments were made utilizing annealed $\mathrm{Au}(111)$ electrodes their initial topography being that already described in section 3.1 above. For both aqueous sulfuric and perchloric acids, the voltammograms were run at $v=0.05 \mathrm{~V} \mathrm{~s}^{-1}$ according to routine I starting from $E_{\mathrm{i}}=$ $0.50 \mathrm{~V}$ up to different values of $E_{\mathrm{as}}$, this potential was held for 

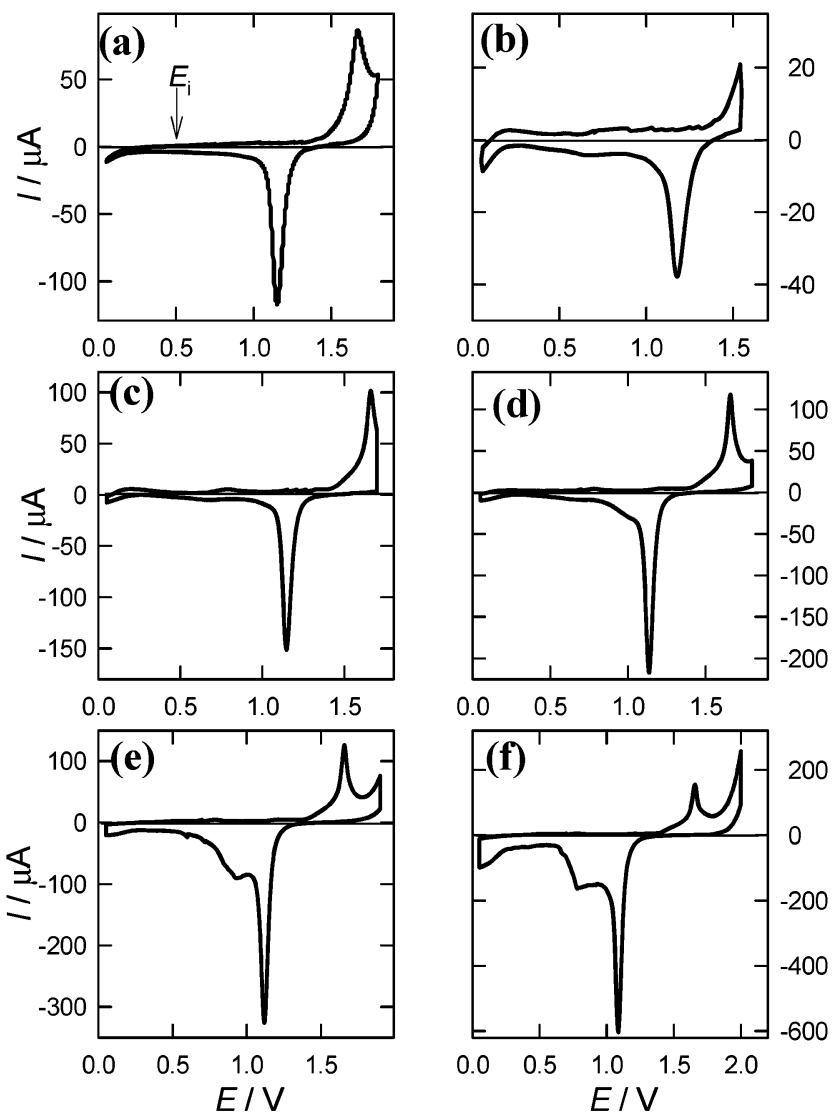

Figure 3. Voltammograms of $\mathrm{Au}(111)$ single-crystal electrodes in 1 $\mathrm{M}$ aqueous sulfuric acid run at $v=0.05 \mathrm{~V} \mathrm{~s}^{-1}$ from $E_{\mathrm{i}}=0.5 \mathrm{~V}$ to (a) $E_{\text {as }}=1.80 \mathrm{~V}$ (blank); (b) $1.55 \mathrm{~V}$; (c) $1.70 \mathrm{~V}$; (d) $1.80 \mathrm{~V}$; (e) $1.90 \mathrm{~V}$; (f) $2.00 \mathrm{~V}$. Note the different current scales in the graphs. The voltammograms change considerably with $E_{\text {as }}$.

$t_{\mathrm{ag}}$, and then the potential scan was reversed to $-0.25 \leq E_{\mathrm{cs}} \leq$ $0.05 \mathrm{~V}$. The value of $E_{\mathrm{i}}$ was slightly more negative than the potential of zero charge of $\mathrm{Au}(111)$ in aqueous acids, $E_{\mathrm{pzc}} \cong$ $0.55 \mathrm{~V}$ at $298 \mathrm{~K},{ }^{49}$ which lies in the double layer potential range of the voltammogram. Blanks for both acids are depicted in Figures $3 \mathrm{a}$ and $5 \mathrm{~b}$.

3.2.1. 1.0 M Aqueous Sulfuric Acid. Single sweep voltammograms from either reconstructed or unreconstructed $\mathrm{Au}(111)$ in aqueous sulfuric acid run from $E_{\mathrm{cs}}=0.05 \mathrm{~V}$ up to different values of $E_{\text {as }}$ show distinguishable features related to anodic and cathodic processes that depend on $E_{\text {as }}$ and $t_{\text {ag }}$. Thus, the voltammogram run from $E_{\mathrm{i}}=0.50 \mathrm{~V}$ to $E_{\text {as }} \leq 1.7 \mathrm{~V}$, held at this potential for $t_{\mathrm{ag}}=30 \mathrm{~s}$, and backward to $E_{\mathrm{cs}}=0.05 \mathrm{~V}$ (Figure $3 b, c)$ shows a first current signal at $0.75 \mathrm{~V}$ associated with the lifting of $\mathrm{Au}(111)$ reconstruction ${ }^{50-53}$ and the initiation of sulfate ion specific adsorption, ${ }^{53-58}$ followed by an anodic current peak at $1.65 \mathrm{~V}$ preceded by a small hump at ca. $1.50 \mathrm{~V}$. The reverse scan exhibits a single sharp cathodic peak at 1.15 $\mathrm{V}$. In this case, for $E_{\text {as }}=1.70 \mathrm{~V}$, the anodic voltammetric charge is $q_{\mathrm{a}}=0.46 \mathrm{mC} \mathrm{cm}^{-2}$, a figure close to $q_{\mathrm{a}}=0.444 \mathrm{mC} \mathrm{cm}^{-2}$, the charge density calculated for one ML of oxygen atoms on a $\mathrm{Au}(111)$ crystal surface. ${ }^{51-53}$

A similar voltammogram run to $E_{\text {as }}=1.80 \mathrm{~V}$ (Figure 3d) adds a complex cathodic peak at ca. $0.90 \mathrm{~V}$ that further increases and extends to approximately $0.60 \mathrm{~V}$ as $E_{\text {as }}$ is shifted positively to $E_{\mathrm{as}}=1.90 \mathrm{~V}$ (Figure 3e). Otherwise, the voltammogram run up to $E_{\text {as }}>1.90 \mathrm{~V}$ (Figure 3f) shows the increase in the current related to the oxygen evolution reaction on a gold surface that is already fully covered by an adsorbed oxo-hydroxide multilayer a few ML thick. In this case, the molecular oxygen
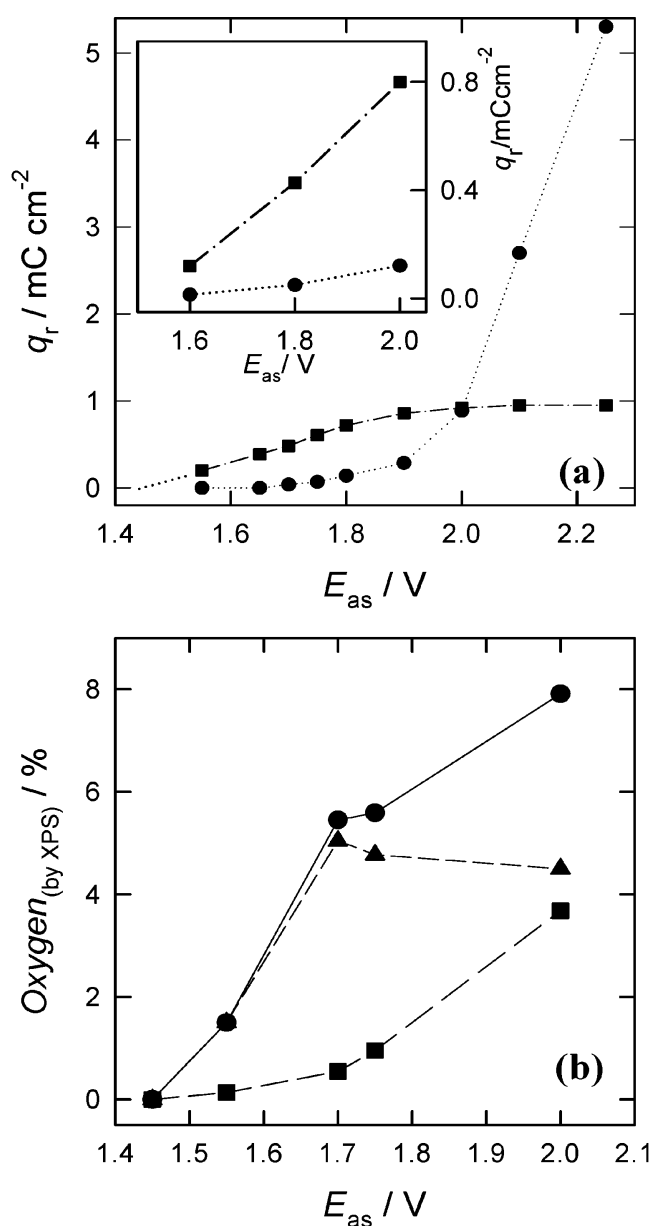

Figure 4. Dependence of the amount of $\mathrm{O}$ - and $\mathrm{OH}$-containing surface species on the anodic switching potential. (a) Plots of $q_{\mathrm{r}}$ versus $E_{\mathrm{as}}$ from voltammetric data obtained in $1 \mathrm{M}$ aqueous sulfuric acid as shown

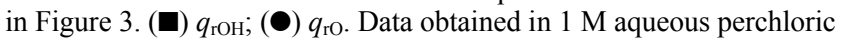
acid are depicted in the inset. (b) Plots of the height of deconvoluted XPS O1s peaks related to the presence of $\mathrm{OH}(\boldsymbol{\Delta})$ and $\mathrm{O}(\boldsymbol{\square})$ surface species versus $E_{\text {as }}$. The sum of oxygen species (\%) $\mathrm{OH}+\mathrm{O}(\boldsymbol{\bullet})$ is also plotted.

electroreduction limiting current that extends from $E<0.50 \mathrm{~V}$ downward is related to the four-electron-transfer reaction involving two consecutive electron-transfer steps. ${ }^{59,60}$ In contrast to results obtained for $E_{\mathrm{as}} \leq 1.80 \mathrm{~V}$, when $E_{\mathrm{as}}=2.00 \mathrm{~V}$ (Figure $3 \mathrm{f}$ ), the voltammetric charge from the electroreduction of the oxygen-containing layer contributes to the enhancement of the cathodic peak at ca. $0.90 \mathrm{~V}$.

Voltammograms for $E_{\mathrm{as}}>1.80 \mathrm{~V}$ show that the potential of the current peak for oxygen adlayer electroreduction shifts negatively as $q_{\mathrm{a}}$ increases, in agreement with previously published results. ${ }^{36-44}$ The dependence on $E_{\text {as }}$ of the oxygencontaining adlayer electroreduction charge density $\left(q_{\mathrm{r}}\right)$ resulting from the cathodic current peaks at 0.90 and $1.18 \mathrm{~V}$ is shown in Figure 4a.

3.2.2. 1.0 M Aqueous Perchloric Acid. In general, the voltammogram from an initially reconstructed $\mathrm{Au}(111)$ sample (Figure 5a) in $1 \mathrm{M}$ aqueous perchloric acid is comparable to those described in 3.1.2 (Figure 5a). The voltammogram run with the same routine described in 3.2.1 (Figure 5b) exhibits small current instabilities in the range 0.50 to $0.90 \mathrm{~V}$, which are presumably related to lifting of the $\mathrm{Au}(111)$ surface reconstruction. ${ }^{18-21}$ The formation of the oxygen-containing layer commences at $E=1.15 \mathrm{~V}$. It is characterized by an anodic current peak at $1.65 \mathrm{~V}$ that is preceded by a small hump. No feature specific to perchlorate ion adsorption on $\mathrm{Au}(111)$ can 


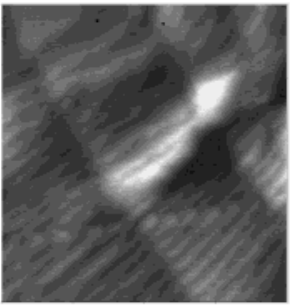

(a)
$E / V$

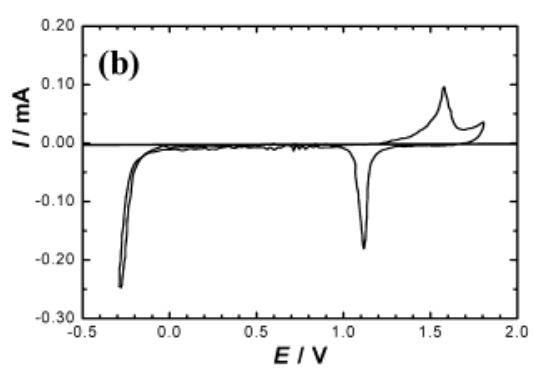

Figure 5. (a) In-situ STM $\left(100 \times 100 \mathrm{~nm}^{2}\right)$ of a $\mathrm{Au}(111)$ singlecrystal surface in $1 \mathrm{M}$ aqueous perchloric acid at $E_{\mathrm{i}}=0.5 \mathrm{~V}$. The 22 $\times \sqrt{ } 3$ lattice of reconstructed $\mathrm{Au}(111)$ surface dominates the topography. (b) Voltammograms of a $\mathrm{Au}(111)$ single-crystal electrode in 1 $\mathrm{M}$ aqueous perchloric acid run at $v=0.10 \mathrm{~V} \mathrm{~s}^{-1}$ from $E_{\mathrm{i}}=0.50 \mathrm{~V}$ to $E_{\text {as }}=1.80 \mathrm{~V}$, reversed to $E_{\mathrm{cs}}=-0.30 \mathrm{~V}$, and backward to $0.50 \mathrm{~V}$.

be distinguished in the voltammogram. The reverse potential scan shows a main cathodic current peak at $1.18 \mathrm{~V}$. The molecular oxygen electroreduction wave extends from $E<0.55$ $\mathrm{V}$ downward. For the same $E_{\text {as }}$, the charge derived from the voltammetric peaks at 1.00 and $0.50 \mathrm{~V}$ that corresponds to the amount of oxygen-containing adsorbates on $\mathrm{Au}(111)$ in aqueous perchloric acid is smaller than that in aqueous sulfuric acid. Values of $q_{\mathrm{r}}(0.90 \mathrm{~V})$ and $q_{\mathrm{r}}(1.18 \mathrm{~V})$ at different $E_{\mathrm{as}}$ for $\mathrm{Au}(111)$ in $1 \mathrm{M}$ aqueous perchloric acid are shown in Figure $4 \mathrm{a}$ (inset).

3.3. STM Imaging. 3.3.1. Application of Routines I and II. Influence of $E_{\text {as }}$. To investigate the electrochemical faceting of $\mathrm{Au}(111)$ changes in the sample topography were followed by STM imaging, first after the application of routine I from $E_{\mathrm{i}}=$ $E_{\mathrm{cs}}$ to $E_{\mathrm{as}}$ and then, after the application of routine II from $E_{\mathrm{as}}$ downward (see arrows in Figure 1). STM images of Au(111) samples after the application of routine I from $E_{\mathrm{i}}=0.50 \mathrm{~V}$ up to $1.53 \leq E_{\text {as }} \leq 2.00 \mathrm{~V}$ and potential holding at $E_{\text {as }}$ for a preset $t_{\mathrm{ag}}$ involve values of the degree of surface coverage by oxygencontaining species $\left(\theta_{\text {oxy }}\right)$, varying from a subML up to adlayers about 2 ML thick (Figure 4a).

The STM image, rather disordered and diffuse, is obtained after the first electro-oxidation scan up to $E_{\mathrm{as}}=1.53 \mathrm{~V}$ and $t_{\mathrm{ag}}$ $=20 \mathrm{~s}$ (Figure 6a). This image shows the formation of small bumps, the appearance of randomly distributed holes of smaller size than that of bumps, and steps somewhat distorted separating terraces. As seen from the cross section analysis, the height of these defects is close to the diameter of the gold atom, and the corrugation at terraces is a fraction of gold atom size, as has been reported for O-atom adsorbates on several metals. ${ }^{61}$ Conversely, the definition of the STM image resulting after the subsequent electroreduction scan from $E_{\text {as }}$ to $E_{\mathrm{i}}$ (Figure 6b) is better defined. It shows the formation of bumps and holes 2-5 $\mathrm{nm}$ wide and about $0.24 \mathrm{~nm}$ high randomly distributed on terraces containing about $(3-7) \times 10^{4}$ and 200-500 gold atoms, respectively, and a distortion of step edges. Both bumps and holes tend to acquire a triangular shape. After the second electrooxidation scan, the STM image (Figure 6c) exhibits an increasing destruction of step edges, terraces becoming rounded, and a number of small diffuse bumps and holes, their cross section being distinguishable from the noise of the preceding profile (Figure 6a). The STM image after the subsequent electroreduction scan (Figure 6d) shows the formation of small crystallites with neat faces and steps separating terraces. In contrast to holes, which are randomly distributed on terraces and steps, only a few small nanometer-sized bumps remain on terraces. Then, the appearance of the surface can be described as a "Swiss cheese-like" structure. The cross section analysis indicates an early stage of faceting, i.e., small crystallites separated by holes 1-2 gold atoms deep. Holes of different size and shape, most of them one gold atom high, are formed on terraces. It should be noted that the electrooxidized $\mathrm{Au}(111)$ surface, in contrast to the electroreduced one, exhibits a small corrugation noise (about $0.05 \mathrm{~nm}$ ) at terraces. A zoom of these features (Figure $6 \mathrm{e}$ ) indicates a tendency to the formation of crystalline nanopits with faces forming $30^{\circ}$ angles or multiples of it. The coalescence of a relatively large number of bumps generates continuous grain-like surface domains (clustering) and holes of different sizes from the nanometer-scale upward. After the third electrooxidation scan (Figure 6f) the image of the surface shows step edges rather diffuse, and a sort of aligned diffuse wormlike grains (clusters) at both the center and at the central upper part of the image. After the subsequent electroreduction scan (Figure $6 \mathrm{~g}$ ) the image, at $E_{\mathrm{i}}=0.5 \mathrm{~V}$, is qualitatively similar to that shown in Figure 6e, but the shape and distribution of terraces, bumps, and holes have changed drastically, although the height of all these defects is always equal or close to one gold atom height. It is interesting to observe that if the image of the same surface domain is repeated $7 \mathrm{~min}$ later (Figure $6 \mathrm{~h}$ ), remarkable differences in the topography reveal the occurrence of coalescence phenomena leading to changes in the number and size of holes and bumps, as well as in the shape and size of terraces. The cross section of the "aged" electrode shows an increase in the overall surface smoothness.

The sequence of STM images after electro-oxidation from $E_{\mathrm{i}}=0.50 \mathrm{~V}$ to $E_{\mathrm{as}}=1.65 \mathrm{~V}\left(\theta_{\text {oxy }} \rightarrow 1\right)$ is depicted in Figure 7. After the first electro-oxidation scan (Figure 7a), the surface appears mostly covered by a large number of small clusters $1-2$ $\mathrm{nm}$ in average size, either free or contacting neighbor clusters, and a few bumps and holes $5-10 \mathrm{~nm}$ in average size randomly distributed. A considerable number of small size clusters are rounded while larger bumps tend to attain a triangular shape. Terrace domains covered by small clusters exhibit a corrugation of about $0.05 \mathrm{~nm}$. The cross section analysis indicates that step edges about one gold atom high are somewhat distorted. As discussed further on, the small clusters with $0.05 \mathrm{~nm}$ corrugation can be related to the presence of $\mathrm{O}$ - and $\mathrm{OH}$-adsorbates. After the subsequent electroreduction scan down to $E_{\mathrm{i}}=0.50 \mathrm{~V}$ (Figure 7b), the small clusters disappear and the formation of holes $1-10 \mathrm{~nm}$ in average size, irregular step edges, and some rounded bumps about $10 \mathrm{~nm}$ in diameter can be seen. Holes tend to be ordered in certain preferred directions, either following step borders or forming angles with step borders that are multiples of $30^{\circ}$. The average separation distance between neighbor hole centers is close to $20 \mathrm{~nm}$. The depth of holes and the height of bumps are always in the range of one gold atom height. The STM image resulting from the second electrooxidation scan (Figure 7c) repeats the small cluster-like structure all over the surface including the inner part of holes. An increasing density of clusters at regions closer to step edges, and bump formation at terraces due to the coalescence of small clusters are observed. Zoomed images (Figure 7c,d) show further topographic details, such as the tendency to form crystallographic holes. The subsequent electroreduction produces drastic topographic changes characterized by the formation of larger holes, the coalescence of holes yielding the "Swiss cheese"-like pattern with new holes appearing at the level of the second atomic lattice. At this stage, only a very few disklike bumps remain on terraces and very smooth extended terraces are formed.

After the third electro-oxidation scan (not shown) the topographic features described above are maintained, and the coalescence of small bumps yields a structure of parallel sticks covering most of the surface including part of the hole bottoms. 

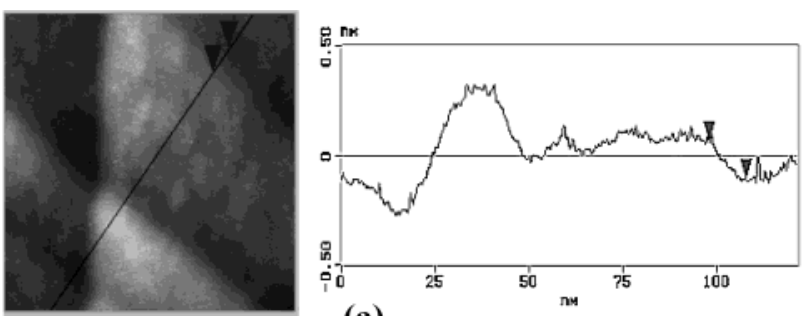

(a)
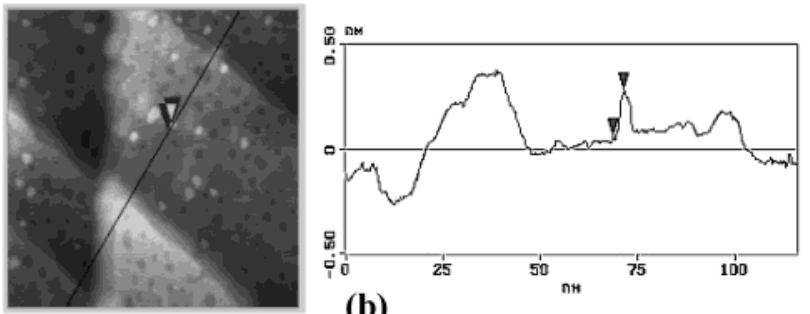

(b)
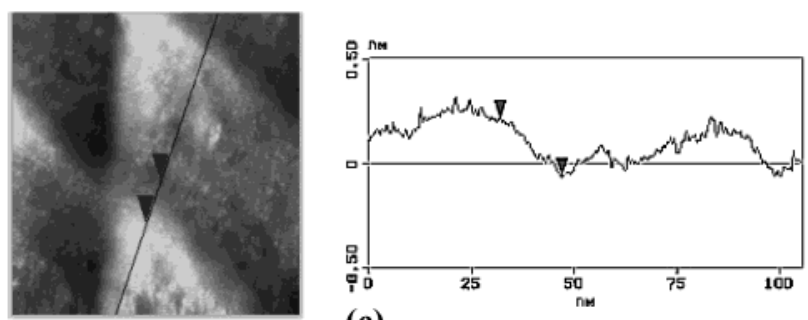

(c)
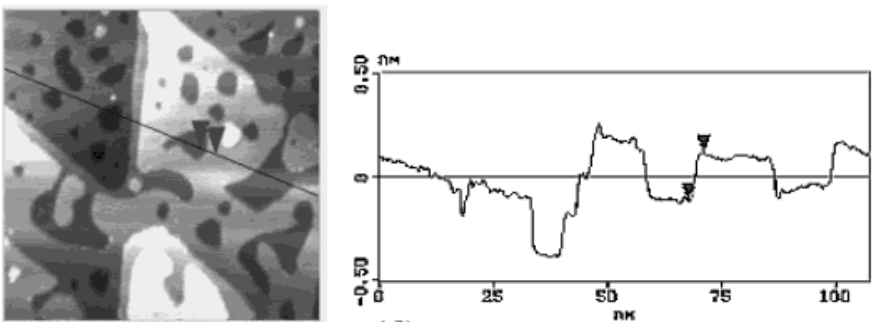

(d)

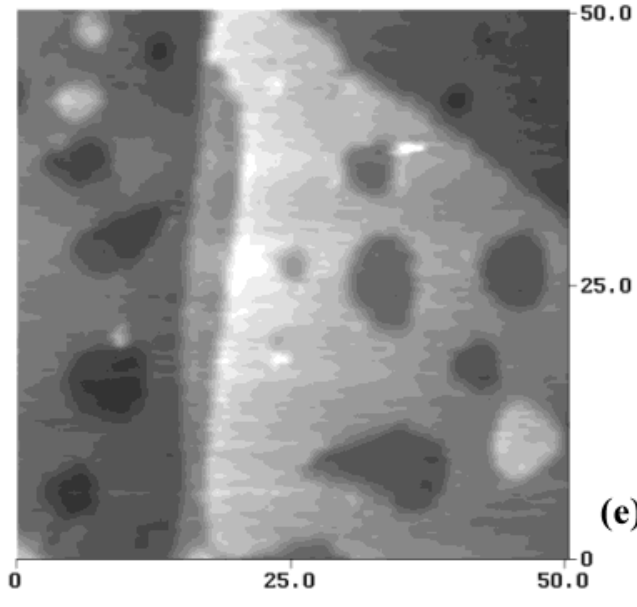

$\mathrm{nm}$
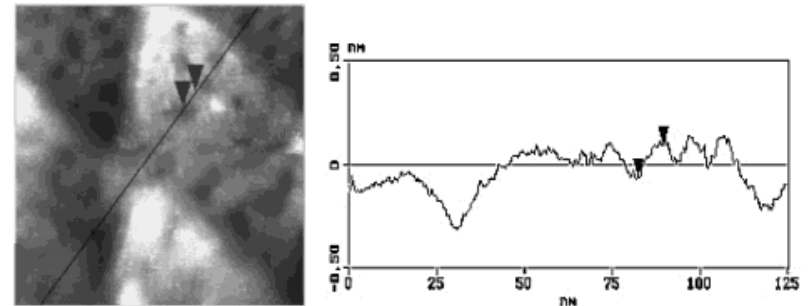

(f)
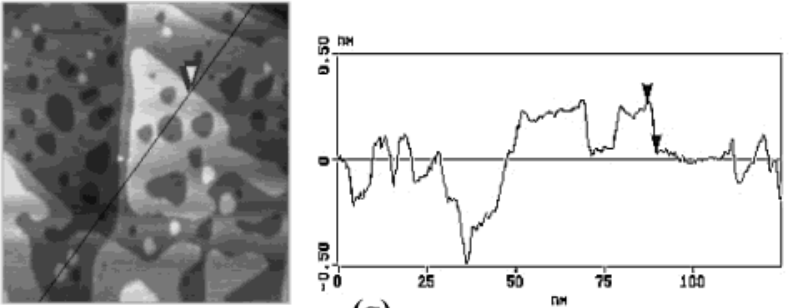

(g)
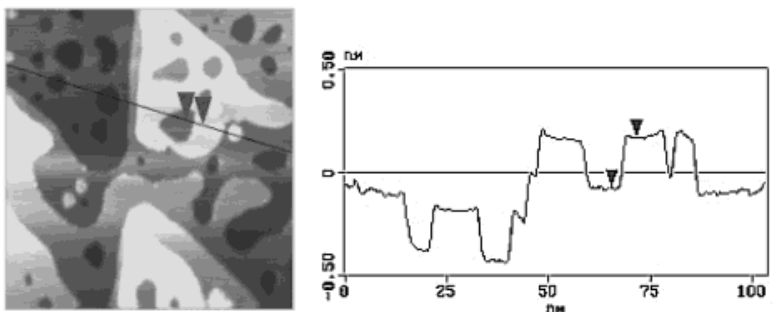

(h)

Figure 6. In-situ STM images $\left(100 \times 100 \mathrm{~nm}^{2}\right)$ of $\mathrm{Au}(111)$ after application of routines I (electro-oxidation) and II (electroreduction). $1 \mathrm{M}$ aqueous sulfuric acid; $E_{\mathrm{i}}=0.50 \mathrm{~V} ; E_{\mathrm{as}}=1.53 \mathrm{~V}$. Routine I: First scan (a); 2nd scan (c); 3rd scan (f). Routine II: First scan (b); 2nd scan (d); 3rd scan (g). Image (e) corresponds to a zoomed domain of image (d). Image (h) shows the topography of image (g) 7 min later. Note the small corrugation resulting from the electro-oxidation scan $(\mathrm{a}, \mathrm{c}, \mathrm{f})$, and hole formation $(\mathrm{b}, \mathrm{d}, \mathrm{g})$ resulting from the electroreduction scan and their evolution (h) observed afterward.

The cross section exhibits bumps and holes approximately one gold atom high with a corrugation of about $0.1 \mathrm{~nm}$. After the electrochemical reduction, the "Swiss cheese"-like structure is enhanced, the area of islands and holes tends to be of the same size, the number density of holes penetrating one atomic layer into bulk gold is increased, and a number of small clusters covering the bare second and third gold layers can be distinguished. The corresponding cross section reveals that the outermost planes of bumps are very smooth, but those of holes exhibit a number of steps one atom high and a corrugation of the order of $0.05-0.07 \mathrm{~nm}$.

The STM images that resulted from the application of routine I from $E_{\mathrm{i}}=0.50 \mathrm{~V}$ up to $E_{\mathrm{as}}=1.78 \mathrm{~V}$ and $t_{\mathrm{ag}}=30 \mathrm{~s},\left(\theta_{\text {oxy }} \rightarrow\right.$ 2 ) to a surface such as that exhibited in Figure 2e, showed a topography of clusters of about $10 \mathrm{~nm}$ average size randomly distributed and terrace domains with a small corrugation as described above. After the application of routine II, a smaller corrugation of the electroreduced surface was observed, the shape of metal clusters became more neat, their average size smaller than that determined for clusters after the electrooxidation stage, and their distribution tending to attain a certain periodicity, as was seen from the cross section analysis.

The STM images resulting from experiments run on a flat $\mathrm{Au}(111)$ terrace in $1 \mathrm{M}$ aqueous perchloric acid by applying first routine I from $E_{\mathrm{i}}=0.50 \mathrm{~V}$ up to $E_{\mathrm{as}}=1.78 \mathrm{~V}$ and $t_{\mathrm{ag}}=$ $30 \mathrm{~s},\left(\theta_{\text {oxy }} \rightarrow 2\right)$ and then routine II showed features comparable to those already described for $1 \mathrm{M}$ aqueous sulfuric acid, although the magnitude of topographic changes was much 

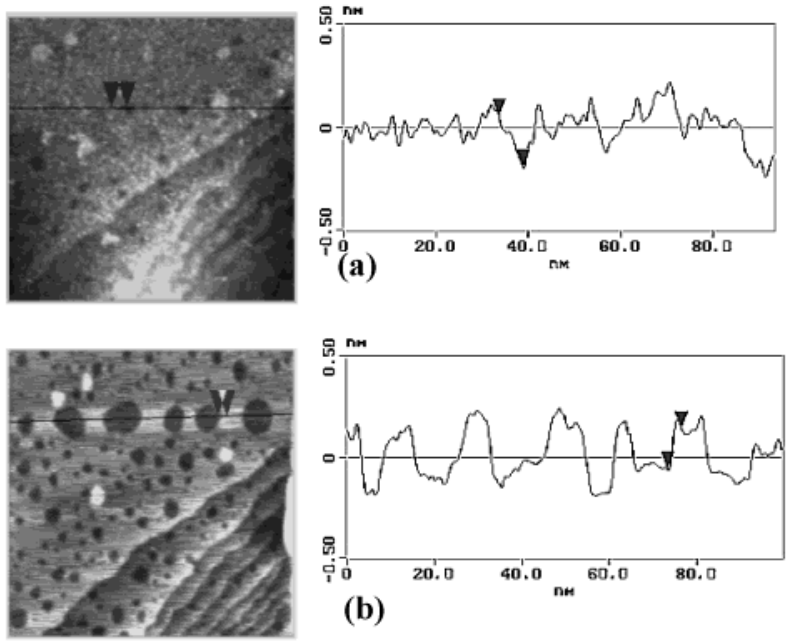

(b)

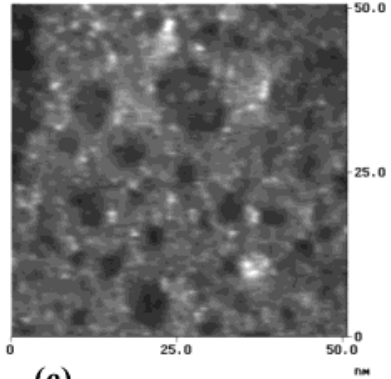

(c)

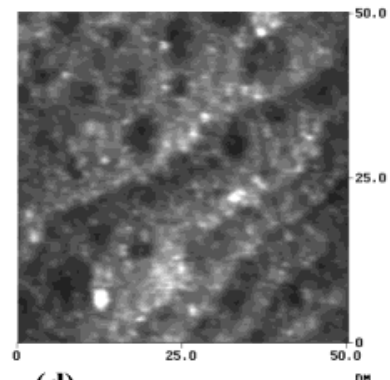

(d)
Figure 7. In-situ STM images $\left(100 \times 100 \mathrm{~nm}^{2}\right)$ of $\mathrm{Au}(111)$ after application of routines I and II. $1 \mathrm{M}$ aqueous sulfuric acid; $E_{\mathrm{cs}}=0.50$ $\mathrm{V} ; E_{\mathrm{as}}=1.65 \mathrm{~V}$. Routine I: First scan (a). Routine II: First scan (b). Images (c) and (d) correspond to zoomed terrace and step domains, respectively, of image (b) after the 2nd electro-oxidation scan.

smaller. The application of routine I generated both relatively wide pits and a large number of small clusters. After the application of routine II, the cross section analysis showed the tendency to a topographic periodicity, which in part might be due to $\mathrm{Au}(111)$ surface reconstruction, as the corrugation 0.042 $\mathrm{nm}$ was much smaller than the gold atom radius. From these experiments one can conclude that the $\mathrm{Au}(111)$ surface atom rearrangement in aqueous perchloric acid caused by the electrochemical treatment is less significant than in aqueous sulfuric acid.

3.3.2. Dynamic Behavior of Au(111) Surfaces after the Electrochemical Treatments in 1 M Aqueous Sulfuric Acid. The sequence of STM images of the same surface domain (Figure 8a) taken after the second electroreduction scan from $E_{\text {as }}$ to $E_{\mathrm{cs}}$ $=0.50 \mathrm{~V}$, holding at this potential for $t=20 \mathrm{~s}$ (Figure 8b), $540 \mathrm{~s}$ (Figure 8c), and $660 \mathrm{~s}$ (Figure 8d), show new features of the dynamics of the electroreduced $\mathrm{Au}(111)$ surface. One of these images (Figure 8a) corresponds to the interruption of the STM scan to visualize the transition between the electrooxidized and the electroreduced domains (lower and upper part of the picture, respectively) of the surface. Considering that for Figure $8 \mathrm{a}$ the scanning frequency is $8 \mathrm{~Hz}$, the image reveals fast changes in the number density, shape and distribution of holes and islands, and shape of step borders that occur in less than 1 s. These changes would involve 2D coalescence of gold adatoms and clusters, as well as competitive adsorption/electrosorption of solution constituents. The rate of these processes decays rapidly as concluded from images depicted in Figure $8 b-d$. However, at longer $t$, as can be seen from the evolution of marked domains in Figure 8b, those lakes initially formed by
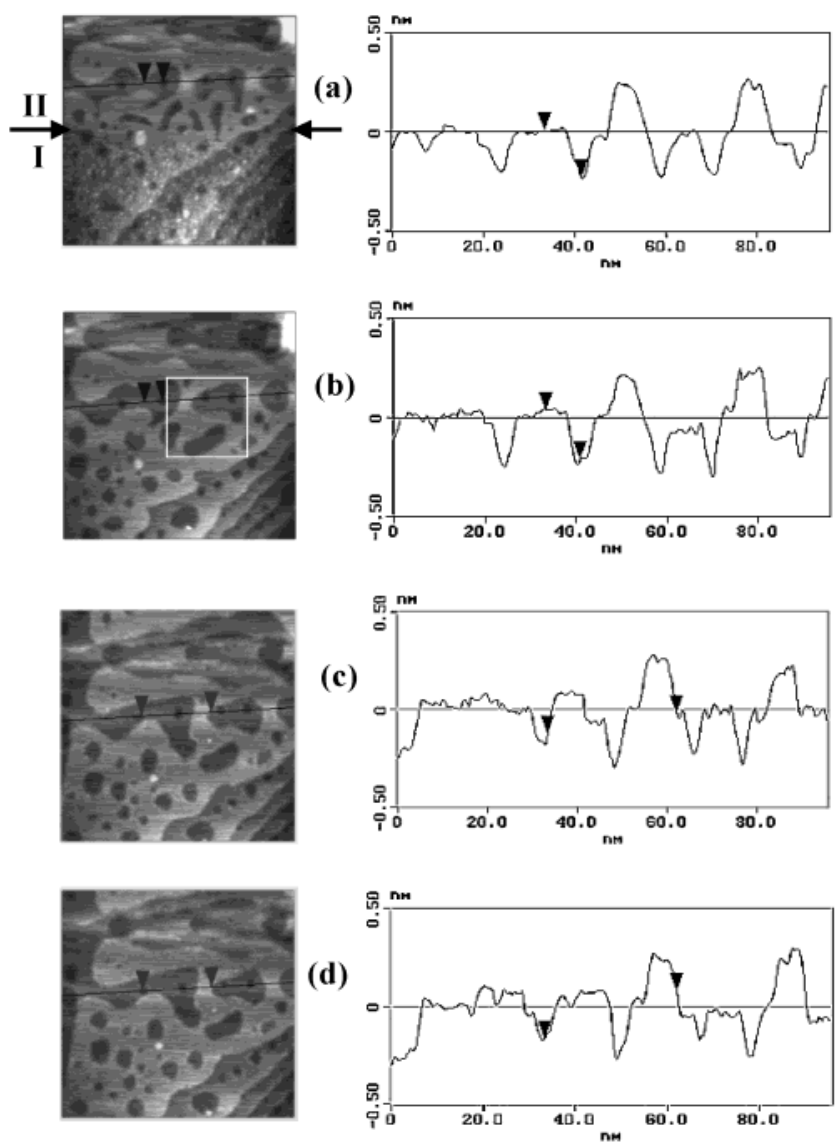

Figure 8. STM images $\left(100 \times 100 \mathrm{~nm}^{2}\right)$ showing the evolution of the topography of a $\mathrm{Au}(111)$ surface domain in $1 \mathrm{M}$ aqueous sulfuric acid after the application of the sequence routine I + routine II + routine I + routine II. STM images of the same surface domain resulting at the end of the second electroreduction scan (routine II) are shown. $E_{\mathrm{i}}$ $=0.50 \mathrm{~V} ; E_{\mathrm{as}}=1.65 \mathrm{~V} ; t_{\mathrm{ag}}=20 \mathrm{~s}$. (a) Image captured interrupting the STM scanning to show the transition in the topography (indicated by the arrows) from the ssecond electro-oxidation to the second electroreduction scan. $(b-d)$ Images of the same electro-reduced domain at $E_{\mathrm{i}}=0.50 \mathrm{~V}$ after $t=45 \mathrm{~s}$ (b); $540 \mathrm{~s}$ (c); $660 \mathrm{~s}$ (d). After electroreduction domains of reconstructed $\mathrm{Au}(111)$ terraces can be observed. The square domain drawn on image (b) was used to determine the kinetics of long-time-range phenomena.

coalescence of holes of smaller size, first reach a maximum area (not shown), and later shrink at a rate much smaller than the coalescence rate. From the cross section analysis of zoomed STM image domains (Figure 8d) for $t>50 \mathrm{~s}$, the directional step edge displacement $\left(X_{\mathrm{d}}\right)$ data obey $X_{\mathrm{d}}$ versus $t^{n}$ plots with exponent values in the range $0.25 \leq n \leq 0.35$, as has been found for Ostwald-type ripening phenomena. ${ }^{61}$ Accordingly, the surface electroreduction reaction is accompanied by the occurrence of short- and long-time-range surface processes. These processes would involve the displacement of atoms and clusters on the surface, and the simultaneous adsorption of anions to allocate gold adatoms into more stable lattice configurations. These atoms either incorporate into the bulk lattice, or more likely form clusters and faceted disc-shaped bumps with sizes compatible with the minimum surface free energy.

On the other hand, a sequence of STM images of the same selected surface domain after the second electro-oxidation scan up to $E_{\text {as }}=1.65 \mathrm{~V}\left(\theta_{\text {oxy }} \cong 0.9\right)$ after $t_{\text {ag }}=30,360$, and $800 \mathrm{~s}$ (Figure $9 a-c$ ) shows that the upper surface of bumps tends to become flatter, and the bottom of holes rougher as $t_{a g}$ is increased, the corresponding corrugation varying from about $0.6 \mathrm{~nm}$ up to one or two gold atoms high. Certainly, the presence 

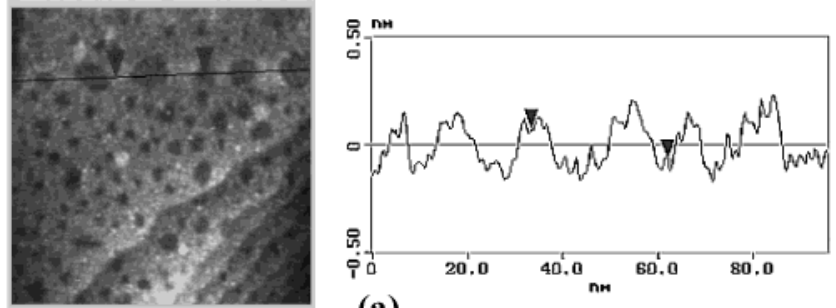

(a)
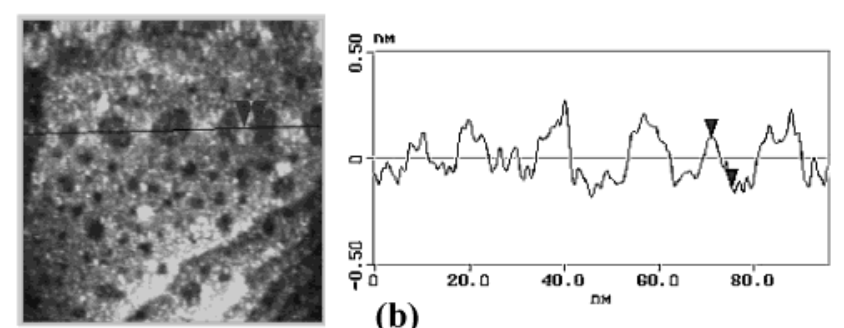

(b)
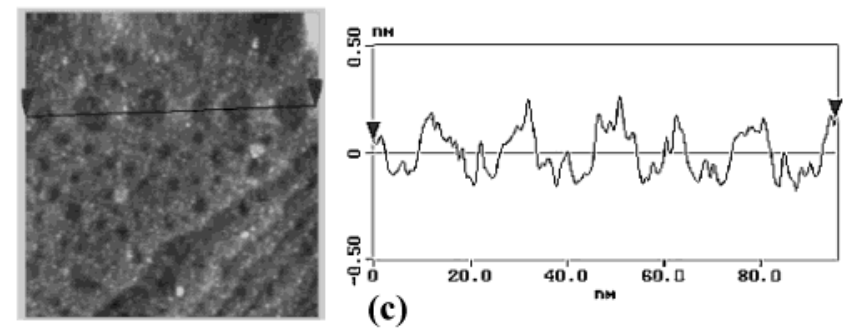

Figure 9. Evolution of the electro-oxidized $\mathrm{Au}(111)$ surface topography for $E_{\text {as }}=1.65 \mathrm{~V}$. STM images $\left(100 \times 100 \mathrm{~nm}^{2}\right)$ of the same domain

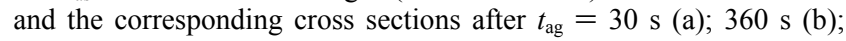
$800 \mathrm{~s}(\mathrm{c})$.

of oxygen on the surface distorts to some extent the smoothness of the surface as discussed further on.

3.4. XPS Data. A detailed XPS study of $\mathrm{Au}(111)$ samples after being subjected to routines I and II, in either $1 \mathrm{M}$ aqueous sulfuric acid or $1 \mathrm{M}$ aqueous perchloric acid, has been made to complement this work. These data were extensively reported elsewhere. ${ }^{48}$

3.4.1. 1.0 M Aqueous Sulfuric Acid. Reference XPS data were obtained from an annealed $\mathrm{Au}(111)$ electrode in $1 \mathrm{M}$ aqueous sulfuric acid for $t_{\mathrm{ag}}=15 \mathrm{~min}$ at $E_{\mathrm{oc}}=0.80 \mathrm{~V}$, a value close to the open circuit potential of the system. The survey XPS spectrum (Figure 10a) shows signals at $84.05 \mathrm{eV}\left(\mathrm{Au} 4 \mathrm{f}_{7 / 2}\right)$ and $87.70 \mathrm{eV}\left(\mathrm{Au}_{4} \mathrm{f}_{5 / 2}\right)$ with fwhm $=0.7 \mathrm{eV}$, in agreement with reference data, ${ }^{54-57}$ and multiplex signals at $169.1 \mathrm{eV}\left(\mathrm{S} 2 \mathrm{p}_{3 / 2}\right)$, $532 \mathrm{eV}(\mathrm{O} 1 \mathrm{~s})$, and $286.3 \mathrm{eV}(\mathrm{C} 1 \mathrm{~s})$. The $\mathrm{S} 2 \mathrm{p}_{3 / 2}$ signal is related to the presence of adsorbed sulfate species. This signal was taken as a reference for calibration of the surface coverage by adsorbates. According to the literature, ${ }^{23,51-54}$ at $E_{\mathrm{oc}}=0.80 \mathrm{~V}$ the largest coverage of $\mathrm{Au}(111)$ by adsorbed sulfate ions $\left(\theta_{\text {sulfate }}\right)$ from aqueous sulfuric acid, $\theta_{\text {sulfate }} \cong 0.2$, is attained. This value decreases at potentials where sulfate adsorption competes with the formation of the oxygen-containing layer.

The XPS of a $\mathrm{Au}(111)$ electrode potential scanned from 0.5 $\mathrm{V}$ up to $E_{\text {as }}$ in the range $1.55 \leq E_{\mathrm{as}} \leq 2.50 \mathrm{~V}$ and holding at $E_{\text {as }}$ for $30 \leq t_{\mathrm{ag}} \leq 300 \mathrm{~s}$ (Figure 10b) shows the same Au signals already described, and a multiplex O1s spectrum peak revealing the existence of different oxygen-containing species on the surface. The value of the oxygen-containing adlayer on $\mathrm{Au}(111)$ was determined by integrating the anodic voltammetric charge and considering $q_{\mathrm{a}}=0.444 \mathrm{mC} \mathrm{cm}^{-2}$ for the oxygen-atom ML on $\mathrm{Au}(111) .{ }^{29}$ The deconvolution of the O1s signal (Figure 11) of samples electro-oxidized at different $E_{\text {as }}$ suggests the presence

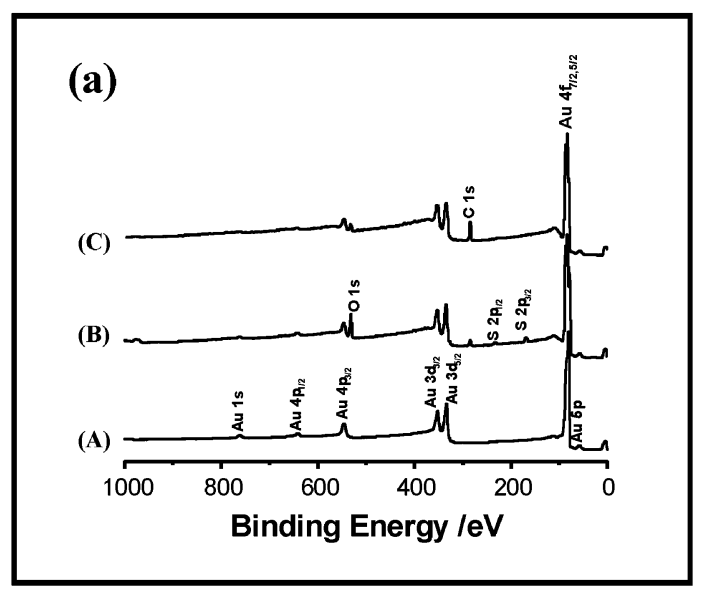

(b)

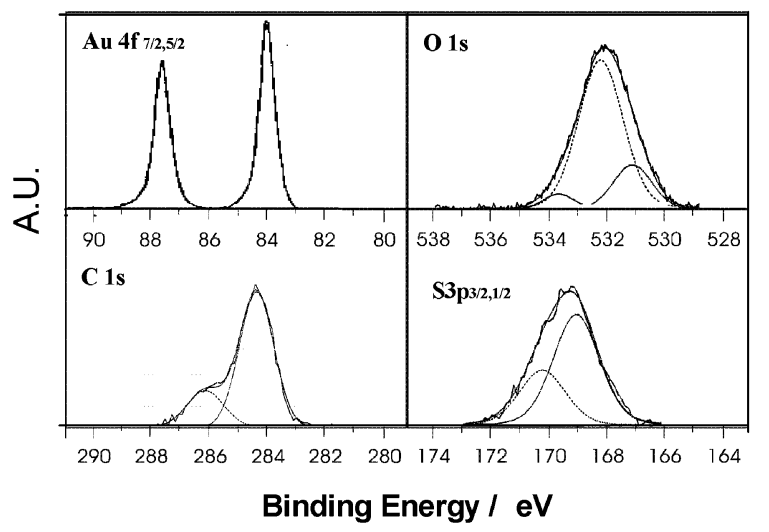

Figure 10. (a) Survey XPS spectra. (A) Au(111) sample after argon sputtering (blank). (b) Gold sample after immersion in $1 \mathrm{M}$ aqueous sulfuric acid, electro-reduced at $0.05 \mathrm{~V}$ for $2 \mathrm{~min}$ and removed from the solution at $0.5 \mathrm{~V}$. (C) The same treatment as in (B), but in $1 \mathrm{M}$ aqueous perchloric acid; $298 \mathrm{~K}$. (b) XPS spectral regions of gold, oxygen, carbon, and sulfur, and curve-fitting analysis after holding the $\mathrm{Au}(111)$ sample at $E=0.80 \mathrm{~V}$ for $15 \mathrm{~min}$ in $1 \mathrm{M}$ aqueous sulfuric acid.

of four oxygen-containing species together with signals from sulfate $(\mathrm{BE}=531.5 \mathrm{eV})$ and carbonaceous residues $(\mathrm{BE}=532.3$ eV) (Figure 11). To discriminate those species specifically produced by the electrochemical treatment from those resulting from impurities coming from the environment, a correlation between deconvoluted spectra and voltammetric electroreduction peaks was established (Figure 4a,b). Thus, for $E_{\text {as }}=1.55 \mathrm{~V}$, the first deconvoluted peak at $531.3 \mathrm{eV}$ is assigned to $\mathrm{C}-\mathrm{O}$ species: the peak at $532.3 \mathrm{eV}$ to sulfate adsorbates, the peak at 531.1. eV to $\mathrm{OH}-\mathrm{Au}$, and the peak at $533.3 \mathrm{eV}$ to $\mathrm{O}-\mathrm{Au}$ surface species. The intensity of the latter is consistent with the voltammetric charge of the electroreduction current peak at $1.55 \mathrm{~V}$.

A summary of data derived from the deconvolution analysis of the $\mathrm{O} 1 \mathrm{~s}$ signal is depicted in Figure $4 \mathrm{~b}$. The binding energies (BE) of oxygenated surface species in $1 \mathrm{M}$ aqueous sulfuric acid, and the elemental adlayer composition are shown in Table 1.

3.4.2. 1.0 M Aqueous Perchloric Acid. Under comparable conditions, XPS results for $\mathrm{Au}(111)$ in $1.0 \mathrm{M}$ aqueous perchloric acid are similar to those described in section 3.2.1, except for the absence, as expected, of the sulfur atom signal. Thus, from $1.60 \mathrm{~V} \leq E_{\text {as }} \leq 2.00 \mathrm{~V}$, after electrode emersion the XPS shows all expected peaks, including the smallest contribution of $\mathrm{O} 1 \mathrm{~s}$ and $\mathrm{C} 1 \mathrm{~s}$ peaks due to contamination by traces of chlorine- and 


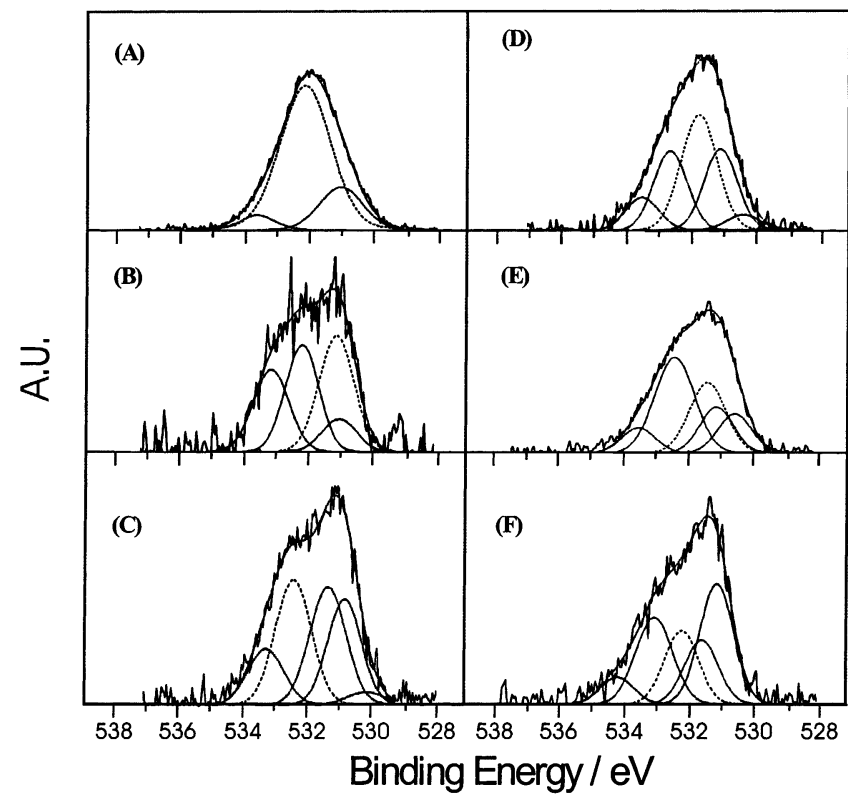

Figure 11. Deconvolution of the XPS O1s signal. Au(111) samples treated in $1 \mathrm{M}$ aqueous sulfuric acid as indicated in the text. (A) $E=$ $0.80 \mathrm{~V}$; (B) $E_{\text {as }}=1.55 \mathrm{~V}$; (C) $E_{\text {as }}=1.65 \mathrm{~V}$; (D) $E_{\text {as }}=1.75 \mathrm{~V}$; (E) $E_{\text {as }}$ $=2.00 \mathrm{~V} ;(\mathrm{F}) E_{\mathrm{as}}=2.50 \mathrm{~V}$. The deconvoluted XPS signals at 532.3 and $531.5 \mathrm{eV}$ correspond to residual sulfate and carbonaceous species.

TABLE 1: Summary of the Deconvolution Analysis of the XPS O1s Signal ${ }^{a}$ (The binding energy, the composition of oxygenated surface species, and their percent elemental adlayer composition (in parentheses) are indicated.)

\begin{tabular}{cccc}
\hline & \multicolumn{3}{c}{ binding energy of oxygenated species $(\mathrm{eV})^{b}$} \\
\cline { 2 - 4 }$E_{\text {as }}(\mathrm{V})$ & $\mathrm{Au}-\mathrm{H}_{2} \mathrm{O}$ & $\mathrm{Au}-\mathrm{OH}$ & $\mathrm{Au}-\mathrm{O}$ \\
\hline 0.80 & $533.7(1.6 \%)$ & N.D. & N.D. \\
1.55 & $533.3(3.7 \%)$ & $531.2(1.4 \%)$ & N.D. \\
1.70 & $533.3(2.8 \%)$ & $530.9(4.9 \%)$ & $530.2(0.6 \%)$ \\
1.75 & $533.6(1.9 \%)$ & $531.2(4.7 \%)$ & $530.5(0.9 \%)$ \\
2.00 & $533.6(2.3 \%)$ & $531.2(4.3 \%)$ & $530.6(3.6 \%)$ \\
2.50 & $534.2(1.8 \%)$ & $531.7(4.3 \%)$ & $531.3(8.2 \%)$
\end{tabular}

${ }^{a} \mathrm{Au}(111) / 1 \mathrm{M}$ aqueous sulfuric acid. Data are corrected for sulfate ion adsorption as indicated in ref $48 .{ }^{b}$ N.D. $=$ nondetectable.

TABLE 2: Summary of the Adlayer Elemental Composition $^{a}$ (Data from the deconvolution of the XPS O1s signal. Au(111)/1M aqueous perchloric acid.)

\begin{tabular}{cccc}
\hline & \multicolumn{3}{c}{ binding energy of oxygenated species $(\mathrm{eV})$} \\
\cline { 2 - 4 }$E_{\text {as }}(\mathrm{V})$ & $\mathrm{Au}-\mathrm{H}_{2} \mathrm{O}$ & $\mathrm{Au}-\mathrm{OH}^{b}$ & $\mathrm{Au}-\mathrm{O}$ \\
\hline 0.80 & $532.7(3.1 \%)$ & N.D. & N.D. \\
1.60 & N.D. & $531.3(0.7 \%)$ & N.D. \\
2.00 & N.D. & $531.5(2.7 \%)$ & $531.0(1.9 \%)$
\end{tabular}

${ }^{a}$ N.D. $=$ nondetectable. ${ }^{b}$ Adsorbed species related to the voltammetric electroreduction current peak at $1.17 \mathrm{~V}$.

carbon-oxygen-containing species, respectively. The presence of traces of chloride as an impurity from perchloric acid may contribute to the formation of a weakly adsorbed layer that presumably consists of chloride, perchlorate, and water. ${ }^{62,63}$ The corresponding summary of data resulting from the deconvolution of the O1s signal for $\mathrm{Au}(111)$ in $1 \mathrm{M}$ aqueous perchloric acid are assembled in Table 2.

\section{Discussion}

4.1. Preliminary Considerations. Both XPS and voltammetric data of anodized $\mathrm{Au}(111)$ depend on the strength of anion adsorption on the substrate in agreement with the key role played by anions at the polarized electrochemical interface that has been discussed in earlier publications..$^{23,50-53}$

For $\mathrm{Au}(111)$ in aqueous sulfuric acid, the specific adsorption of sulfate ions starts at $E \cong 0.35 \mathrm{~V}$, i.e., on the negatively charged surface $\left(E<E_{\text {pze }} \cong 0.5 \mathrm{~V}\right)$. Electrochemical data ${ }^{23,27,55}$ have shown that the surface concentration of sulfate species initially changes slowly with $E$, it rises steeply for $E>E_{\mathrm{pzc}}$, and finally, for $E>0.7 \mathrm{~V}$, an ordered adlayer packing density close to saturation is attained. ${ }^{19,55}$ The lifting of $\mathrm{Au}(111)$ surface reconstruction occurs at very small coverages of adsorbed sulfate. ${ }^{56,58}$ In-situ STM imaging of $\mathrm{Au}(111)$ immersed in aqueous sulfuric acid has shown an order-disorder transition in the sulfate/bisulfate adlayer. ${ }^{18,64}$ The ordered adlayers are observed in the potential range where the $\operatorname{Au}(111)(1 \times 1)$ surface structure is stable. ${ }^{18,53,65}$ Similar ordered adlayer structures have been observed from $\mathrm{Au}(111)$ emersed from sulfatecontaining solution. ${ }^{18,23,66}$

The commensurate structure involves a maximum surface coverage equivalent to $\theta_{\text {sulfate }} \cong 0.2$, a figure significantly lower than that expected for a close packed sulfate adlayer. This adlayer consists of sulfate/bisulfate anions bound to the surface with their oxygen atoms toward the metal surface, matching the tetragonal symmetry of the anions and the trigonal (111) surface lattice, ${ }^{18,23,66-70}$ in agreement with recent calculations of the adsorption of sulfate adlayer on $\mathrm{Au}(111) .{ }^{67} \mathrm{~A}$ dynamic model of the adlayer has also been proposed ${ }^{67-70}$ in which the adlayer array consists of a sulfuric acid/water coadsorbed layer via hydrogen bonding, similar to that of oxonion hydrogen sulfate. ${ }^{70}$ This adlayer structure is stabilized by hydration on top of the $\mathrm{H}_{2} \mathrm{SO}_{4} / \mathrm{H}_{3} \mathrm{O}^{+}$layer. In contrast to aqueous sulfuric acid, no definite ordered adsorbate layer on $\mathrm{Au}(111)$ could be determined in aqueous perchloric acid. This fact points out that the $\mathrm{Au}(111)$-solvated sulfate/bisulfate interaction may depend on the specific hydrogen-bonding capability of each anion. ${ }^{22}$

For $1 \mathrm{M}$ aqueous sulfuric acid, the correlation between XPS data for $\mathrm{OH}$ - and $\mathrm{O}$-adsorbates on $\mathrm{Au}(111)$ and their electrodesorption charge (Figure 4a) shows that the formation of $\mathrm{OH}$ adsorbates starts from $1.45 \mathrm{~V}$, whereas the appearance of O-adsorbates occurs from 1.55 V. The ML charge is attained at $1.70 \mathrm{~V}$, i.e., a potential close to the electroadsorption current peak potential, the corresponding layer being made of $85 \% \mathrm{OH}-$ and $15 \% \mathrm{O}$-adsorbate. The $\mathrm{OH} / \mathrm{O}$ surface concentration ratio decreases as $E_{\text {as }}$ is shifted up to ca. $2.00 \mathrm{~V}$ where a $2 \mathrm{ML}$ thick adsorbed film is formed, the composition of this film approaching the ratio $\mathrm{OH} / \mathrm{O}=1$. At potentials above $1.80 \mathrm{~V}$, in contrast to the concentration of $\mathrm{O}$-species that increases rapidly with the applied potential, the $\mathrm{OH}$ surface concentration remains almost constant. ${ }^{48}$

The above description provides an explanation for the multiplicity of the O1s XPS signal from $\mathrm{Au}(111)$ anodized in $1 \mathrm{M}$ aqueous sulfuric acid. In the absence of carbonaceous residues, this signal involves the contribution of $\mathrm{O}$-atoms from sulfate/bisulfate adsorbates, electroadsorbed $\mathrm{O}$ - and $\mathrm{OH}$-species from water, and water itself, whereas for aqueous perchloric acid, only the last two contributions are observed. It should be noted that the XPS signal at $84.0 \mathrm{eV}$ related to the formation of $\mathrm{Au}(\mathrm{III})$ bulk oxide ${ }^{71}$ could not be observed in our experiments. ${ }^{48}$ This might be due to the fact that only a thin amorphous hydrous oxide layer is produced by anodization of gold, its nature depending on the potential perturbation routine. ${ }^{72}$ Accordingly, these results and the presence of the XPS water signal over the whole potential range (Figure 4b) confirm that the anodic layer electrochemically produced on $\mathrm{Au}(111)$ for $E_{\mathrm{as}}>$ $1.60 \mathrm{~V}$ can be described as a hydrous amorphous oxo- 
hydroxide adlayer consisting of an $E_{\mathrm{as}}$ and $t_{\mathrm{ag}}$-dependent $\mathrm{OH}$ : $\mathrm{O}: \mathrm{H}_{2} \mathrm{O}$ concentration ratio. Then, the chemical composition of anodic adlayers up to those slightly thicker than $1 \mathrm{ML}$ is well represented as a hydrous oxo-hydroxide layer, as has been earlier concluded. ${ }^{73,74}$

4.2. Likely Complex Molecular Reaction Pathway at the Early Stages of Anodic Layer Formation. 4.2.1. 1.0 M Aqueous Sulfuric Acid. The voltammetric anodic current contribution from $\mathrm{Au}(111)$ in aqueous sulfuric acid starts from ca. $1.45 \mathrm{~V}$, i.e., a potential at which the saturation of adsorbed sulfate on $\mathrm{Au}(111)$ is attained. The corresponding anodic charge has been assigned to the formation of a first sublattice of $\mathrm{OH}^{34-45}$ Therefore, the first elementary step can be described as the discharge of water on a positively charged $\mathrm{Au}(111)$ surface partially covered by sulfate ions. For $E_{\text {as }} \cong 1.45 \mathrm{~V}$ this step can be formally represented by

$$
\begin{aligned}
\left\{\left[\mathrm{Au}_{3}\right]\left(\mathrm{SO}_{4}{ }^{2-}\right)[\mathrm{Au}]\right\}+\mathrm{H}_{2} \mathrm{O}= \\
\left\{\left[\mathrm{Au}_{3}\right]\left(\mathrm{SO}_{4}{ }^{2-}\right)[\mathrm{Au}](\mathrm{OH})\right\}+\mathrm{H}^{+}(\mathrm{aq})+\mathrm{e}^{-}
\end{aligned}
$$

In reaction 1, $3 \mathrm{Au}(111)$ surface atoms on the average would interact with one adsorbed sulfate, and one atom with one $\mathrm{OH}$ species. Adsorbates, gold surface atoms, and surface domains are denoted in parentheses, brackets, and braces, respectively. The half-life time of adsorbed $\mathrm{OH}$ on gold, estimated from fast triangularly modulated triangular potential voltammetry for aqueous acids is in the order of $1 \mathrm{~ms}$ at $298 \mathrm{~K} \cdot{ }^{37-39}$ The relatively fast reaction 1 behaves as a reversible electrochemical surface process.

For values of $E_{\mathrm{as}} \cong 1.65 \mathrm{~V}$, i.e., close to the anodic current peak, the second electron-transfer step involving water electrooxidation increases the surface coverage by $\mathrm{OH}-$ and $\mathrm{O}-$ adsorbates. This process is accompanied by the desorption of sulfate/bisulfate ions from $\mathrm{Au}(111)$, as has been concluded from XPS data. ${ }^{48}$ This reaction can be written as

$$
\begin{aligned}
& \left\{\left[\mathrm{Au}_{3} \mathrm{SO}_{4}{ }^{2-}\right][\mathrm{AuOH}]\left[\mathrm{Au}_{x-2}\right]\right\}+3 \mathrm{H}_{2} \mathrm{O}= \\
& \quad\left\{\left[\mathrm{Au}_{4}(\mathrm{OH})_{4}\right]\left[\mathrm{Au}_{x-2}\right]\right\}+\mathrm{SO}_{4}{ }^{2-}(\mathrm{aq})+3 \mathrm{H}^{+}(\mathrm{aq})+3 \mathrm{e}^{-}
\end{aligned}
$$

and

$$
\begin{array}{r}
\left\{\left[\mathrm{Au}_{3} \mathrm{SO}_{4}{ }^{2-}\right][\mathrm{AuOH}]\left[\mathrm{Au}_{x-2}\right]\right\}+(p+q) \mathrm{H}_{2} \mathrm{O}= \\
\left\{\left[\mathrm{Au}_{n-(p+q)}\right]\left[\mathrm{Au}_{p}(\mathrm{OH})_{p}\right]\left[\mathrm{Au}_{q} \mathrm{O}_{q}\right]\right\}+\mathrm{SO}_{4}{ }^{2-}(\mathrm{aq})+ \\
8(p+2 q) \mathrm{H}^{+}(\mathrm{aq})+(p+2 q) \mathrm{e}^{-}
\end{array}
$$

Reactions 2 and 3 involve complex competitive electrosorption processes and the displacement of the corresponding ionic equilibria at the electrochemical interface.

In agreement with XPS data (Figure 4b), the ratio $p / q$ decreases as $E_{\mathrm{sa}}$ is positively shifted. Then, as the oxygen ML coverage is attained, both $\mathrm{OH}$ - and $\mathrm{O}$-adsorbed species are the main constitutents of the adlayer. Both adsorbates contribute to the formation of the oxo-hydroxide layer at higher surface coverages. ${ }^{47,58}$

The rearrangement of gold surface atoms has been described as a replacement-turnover process associated with eqs 1 to 3..$^{38-45}$ This process, which would involve gold atoms moving up from terrace sites to step positions assisted by competitive electrosorption involving either $\mathrm{OH}$ - or $\mathrm{O}$-adsorbates, can be written via reactions such as

$$
[[\mathrm{Au}]]\{[\mathrm{AuOH}]\} \Longrightarrow\{[\mathrm{AuOH}][\mathrm{Au}]\}
$$

and

$$
[[\mathrm{Au}]]\{[\mathrm{AuO}]\} \Longrightarrow\{[\mathrm{Au} \mathrm{O}][\mathrm{Au}]\}
$$

In reactions 4 and 5 the double brackets indicate gold atoms from the second layer moving upward to the top surface atom layer, whereas $\mathrm{OH}$ - and $\mathrm{O}$-species move slightly inward. This rearrangement of surface species, as discussed further on, agrees with the corrugation of anodized clusters described in sections 3.2.2 and 3.2.3. Reactions 4 and 5 occur in parallel with reactions $1-3$, and contribute to an increase in the disorder of the $\mathrm{Au}(111)$ surface, as concluded from the analysis of STM images. The free energy change involved in these reactions can be estimated as referred to in section 4.3.

4.2.2. 1.0 M Aqueous Perchloric Acid. The weaker adsorption of perchlorate ions on $\mathrm{Au}(111)$, presumably favored by coadsorption with traces of chloride impurity, ${ }^{62,63}$ would contribute to the electrodecomposition of water yielding both $\mathrm{OH}-$ and O-containing adsorbates at values of $E$ lower than those resulting for aqueous sulfuric acid. Therefore, reactions 1 and 2 can be expressed as follows:

$$
\begin{aligned}
& \left\{[\mathrm{Au}]\left(\mathrm{H}_{2} \mathrm{O}\right)[\mathrm{Au}]\left(\mathrm{ClO}_{4}{ }^{-}\right)\right\}+\mathrm{H}_{2} \mathrm{O}= \\
& \quad\left\{[\mathrm{Au}](\mathrm{OH})[\mathrm{Au}]\left(\mathrm{H}_{2} \mathrm{O}\right)\right\}+\mathrm{ClO}_{4}^{-}(\mathrm{aq})+\mathrm{H}^{+}(\mathrm{aq})+\mathrm{e}^{-}
\end{aligned}
$$

and

$$
\begin{aligned}
& \left\{[\mathrm{Au}]\left(\mathrm{H}_{2} \mathrm{O}\right)[\mathrm{Au}](\mathrm{OH})\right\}+\mathrm{H}_{2} \mathrm{O}= \\
& \{[\mathrm{AuOH}][\mathrm{AuO}]\}+2 \mathrm{H}^{+}(\mathrm{aq})+2 \mathrm{e}^{-}
\end{aligned}
$$

For reactions 6 and 7, the weaker perchlorate ion-gold surface interaction would produce a slowdown of reactions 4 and 5, and in this case, the number of gold atoms reallocated per electron-transfer event becomes lower than that found in aqueous sulfuric acid, as discussed in section 4.3.

As concluded from voltammetry and XPS data, in this case the composition of O-containing adlayers a few monolayers thick electroformed from reactions $2-7$ is also consistent with a hydrous $\mathrm{AuOOH}$ surface stoichiometry.

In conclusion, the early stages of the anodic layer formation in both aqueous acids can be reasonably explained in terms of competitive electroadsorption processes coupled to a gold surface atom rearrangement. It should be noted that under our experimental conditions, no $\mathrm{Au}(\mathrm{III})$ oxide phase can be detected at the early stages of anodization, irrespective of the aqueous acid. Hence, our results validate the reaction pathway that has been proposed earlier by several authors from experiments performed with either polycrystalline or single-crystal gold electrodes. ${ }^{34-45}$ Recent data on self-assembled sulfate/bisulfate adlayers on $\mathrm{Au}(111)$ allowed us to extend this reaction pathway including the participation of those adlayers in surface electrochemical reactions. As will be seen, the new approach to the molecular reaction pathway becomes useful to advance in the understanding of $\mathrm{Au}(111)$ faceting.

4.3. Estimation of the Energy Change Associated with the Initiation of Gold Atom Clustering. For $1 \mathrm{M}$ aqueous sulfuric acid, the correlation of XPS and electrochemical data (Figure 4 ) is consistent with the formation of $\mathrm{OH}$-adsorbates via a competitive electroadsorption process as was discussed above. Let us then estimate the energy balance from the first anodization scan up to two different values of $E_{\text {as }}$, i.e., $1.45 \mathrm{~V}$ (Figure $3 \mathrm{a}$ ) and $1.81 \mathrm{~V}$ (Figure $3 \mathrm{e}$ ). Thus, for $E_{\mathrm{as}}=1.45 \mathrm{~V}$, the anodic reaction starts from a $\mathrm{Au}(111)$ surface partially covered by adsorbed sulfate ions 


$$
\begin{aligned}
\mathrm{Au}_{3}\left(\mathrm{SO}_{4}{ }^{2-}\right)(\mathrm{aq})+3 \mathrm{H}_{2} \mathrm{O} & = \\
\mathrm{Au}_{3}(\mathrm{OH})_{3}(\mathrm{aq}) & +\mathrm{SO}_{4}{ }^{2-}(\mathrm{aq})+3 \mathrm{H}^{+}(\mathrm{aq})+3 \mathrm{e}^{-}
\end{aligned}
$$

For $E_{\mathrm{as}}=1.45 \mathrm{~V}$ (versus NHE), the value of $\Delta G_{\mathrm{el}}$, the free energy change associated with reaction 8 , is $\Delta G_{\mathrm{el}}=-3 \mathrm{~F} E_{\mathrm{as}}=$ $\Delta G_{\mathrm{p}}-\Delta G_{\mathrm{r}}$, where $\Delta G_{\mathrm{p}}$ and $\Delta G_{\mathrm{r}}$ stand for the free energy change of products and reactants, respectively. Accordingly, $\Delta G_{\mathrm{el}}=-420 \mathrm{~kJ} \mathrm{~mol}^{-1}$. Let us further consider the enthalpy change accompanying $\mathrm{OH}$ and sulfate adsorption, $\Delta H_{\mathrm{f}}(\mathrm{Au}-$ $\mathrm{OH})=-142 \mathrm{~kJ} \mathrm{~mol}^{-1},{ }^{75,76}$ and the adsorption energy for sulfate/bisulfate on $\mathrm{Au}(111), \Delta G_{\mathrm{ad}}=-140 \mathrm{~kJ} \mathrm{~mol}^{-1}$ at ca. 1.0 $\mathrm{V} .{ }^{18,51,53,64}$ Assuming, as a first approximation, that for both adsorbates $\Delta G_{\mathrm{f}} \cong \Delta H_{\mathrm{f}}$, and disregarding the contribution of $\mathrm{HSO}_{4}{ }^{-}(\mathrm{aq})$ formation from $\mathrm{H}^{+}(\mathrm{aq})$ and $\mathrm{SO}_{4}{ }^{2-}$ (aq) as $\Delta G_{\text {diss }}=$ $-8.67 \mathrm{~kJ} \mathrm{~mol}^{-1},{ }^{77}$ from the energy balance the energy difference $\Delta X=-280 \mathrm{~kJ} \mathrm{~mol}^{-1}$ that would correspond to an excess of energy to be used up for gold surface atom rearrangements. Thus, as gold faceting involves surface stepping, let us take the energy required for the creation of a single atom step on a $\mathrm{Au}(111)$ terrace, that is $\Delta E_{\text {step }} \cong 4.4 \mathrm{~kJ}^{\mathrm{k}}$ atom ${ }^{-1} .{ }^{78}$ Correspondingly, the likely number of atoms involved in the rearrangement of gold surface atoms per event, as represented by reaction 10 , is about 60 . Furthermore, assuming a rounded 2D clustering, the average diameter of each cluster would be on the order of $1 \mathrm{~nm}$.

The same energy balance estimation can be made for $E_{\text {as }}=$ $1.81 \mathrm{~V}$. In this case, XPS and voltammetric data (Figure 4) indicate that the anodic adlayer consists of $\mathrm{OH}$ - and $\mathrm{O}$-species, the latter being slightly in excess with respect to the former. Therefore, the corresponding stoichiometric reaction can be represented as follows:

$$
\begin{aligned}
& \mathrm{Au}(\mathrm{OH})+\mathrm{Au}_{3}\left(\mathrm{SO}_{4}{ }^{2-}\right)+3 \mathrm{H}_{2} \mathrm{O}= \\
& \mathrm{Au}_{2}(\mathrm{OH})_{2}+\mathrm{Au}_{2}(\mathrm{O})_{2}+\mathrm{SO}_{4}{ }^{2-}(\mathrm{aq})+4 \mathrm{H}^{+}(\mathrm{aq})+4 \mathrm{e}^{-}
\end{aligned}
$$

Then, for $E_{\mathrm{as}}=1.81 \mathrm{~V}$, and the value $\Delta H_{\mathrm{f}}(\mathrm{Au}-\mathrm{O})=+27 \mathrm{~kJ}$ $\mathrm{mol}^{-1} 75,76$ from the energy balance the value of $\Delta X$ results in about $500 \mathrm{~kJ} \mathrm{~mol}^{-1}$. This figure would imply that the number of surface atoms removed by each event expressed by reaction 9 is about 100. Accordingly, the average diameter of each round cluster produced for $E_{\mathrm{as}}=1.81 \mathrm{~V}$ would result in about $2 \mathrm{~nm}$.

A similar estimation can be made for $\mathrm{Au}(111)$ anodized in 1 $\mathrm{M}$ aqueous perchloric acid. In this case, the formation of $\mathrm{OH}-$ electroadsorbates is represented by reaction 5 , which involves the electro-oxidation of water at the $\mathrm{Au}(111)$ surface

$$
\begin{aligned}
& \{n[\mathrm{Au}(111)]\}+\mathrm{H}_{2} \mathrm{O}= \\
& \quad\{[(n-1) \mathrm{Au}(111)][\mathrm{Au}(\mathrm{OH})]\}+\mathrm{H}^{+}(\mathrm{aq})+\mathrm{e}^{-}
\end{aligned}
$$

From voltammetry data (Figure 3 ), considering $E=1.30 \mathrm{~V}$ for reaction 10 , and $\Delta H_{\mathrm{f}}\left(\mathrm{Au}-\mathrm{H}_{2} \mathrm{O}\right)=-50 \mathrm{~kJ} \mathrm{~mol}^{-1} 75,76$ one obtains a value $\Delta X$ of about $-33 \mathrm{~kJ} \mathrm{~mol}^{-1}$. This figure would indicate that reaction 5 is accompanied by the formation of a $2 \mathrm{D}$ cluster consisting of 7-8 atoms. Likewise, at $E=1.50 \mathrm{~V}$, considering the reaction

$$
\begin{aligned}
& \{[(n-1) \mathrm{Au}(111)][\mathrm{Au}(\mathrm{OH})]\}+\mathrm{H}_{2} \mathrm{O}= \\
& \quad\{[(n-2) \mathrm{Au}(111)][\mathrm{Au}(\mathrm{OH})][\mathrm{Au}(\mathrm{O})]\}+2 \mathrm{H}^{+}(\mathrm{aq})+2 \mathrm{e}^{-}
\end{aligned}
$$

from the energy balance it results in $\Delta X=-276 \mathrm{~kJ} \mathrm{~mol}^{-1}$. This would mean that reaction 11 involves the clustering of about $60-70$ gold atoms.
These results indicate that the early stages of $\mathrm{Au}(111)$ anodization are closely related to the initiation of faceting, a process that depends considerably on both the interaction of ionic and molecular species with the $\mathrm{Au}(111)$ surface and applied electric potential, i.e., on the relative contribution of the first and the second water electro-oxidation stage to the overall anodization process. Certainly, in our case, the largest efficiency of surface atom rearrangement is obtained in the presence of specifically adsorbed sulfate/bisulfate ions on $\mathrm{Au}(111)$.

4.4. The Early Stages of Faceting. The above molecular approach offers a reasonable explanation to the first stages of gold surface atom reordering produced by anodization, but is insufficient to account for the evolution of topographic features of $\mathrm{Au}(111)$ resulting from the global electro-oxidation and electroreduction cycles. In fact, from the inspection of STM images and depending on the time scale, different relaxation processes taking place at the gold surface can be distinguished, irrespective of both $E_{\text {as }}$ and $\theta_{\text {oxygen. }}$. Results showed that the transition from the electro-oxidized to the electro-reduced surface (Figure 8a) involves a fast electron-transfer reaction in agreement with electrochemical data, ${ }^{34-45}$ followed by surface relaxation producing, at a lower rate, $2 \mathrm{D}$ islands and holes by surface diffusion of either adsorbates or gold adatoms leading in the long term to the appearance of somewhat regular patterns (Figure $8 \mathrm{~b}-\mathrm{d}$ ). These surface relaxation processes can be observed in both the $10 \mathrm{~s}$ range and from 1 min upward. These features, as well as the tendency to clustering of O-containing adsorbates that is observed in the electro-oxidation scan, suggest that the electrochemical faceting could be more realistically discussed in terms of cooperative phenomena.

4.4.1. The Electro-oxidation Stage. The initial formation of $\mathrm{OH}$-adsorbates from water discharge at $E_{\text {as }}=1.45 \mathrm{~V}$ undergoes on the $\mathrm{Au}(111)$ surface partially covered by adsorbed sulfate species, but as $E_{\text {as }}$ is shifted positively and $\theta_{\text {oxy }} \rightarrow 1$, the composition and structure of the $\mathrm{OH} / \mathrm{O}$-containing layer change. In any case, the reproducible hysteresis-free adsorption isotherm of the sulfate ion on $\mathrm{Au}(111)^{23,50-53}$ indicates that the influence of this process on the kinetics of the global electroreduction reaction is smaller than that due to anodic layer aging. ${ }^{79}$

As the surface concentration of $\mathrm{OH}$-species increases, neighbor $\mathrm{OH}$-adsorbates would also contribute to adsorbate clustering via reactions 1 and 2 . The largest density of clusters occurs at step borders (Figures 6 and 7) and their distribution at terraces has been related to the mechanism of clustering. ${ }^{33,79,81}$ The driving force for cluster displacement from terraces to step borders on $\mathrm{Au}(111)$ has been assigned to the gradient of chemical potential between terrace and step borders. ${ }^{81}$ Then, clusters of $\mathrm{OH} / \mathrm{O}$-adsorbates can be considered as precursors for the formation of the oxo-hydroxide layer. ${ }^{80,81}$

On the other hand, from the replacement-turnover processes one would expect the emergence of steps one-gold-atom high, i.e., a $0.24 \mathrm{~nm}$ corrugation at electro-oxidized terraces, a figure that largely exceeds $0.05 \mathrm{~nm}$ as seen from STM images (Figure 12). This small corrugation in the step-terrace topography have been observed for clean $\mathrm{Cu}(110)$ and $\mathrm{Au}(111)^{24,80,81}$ and attributed to adsorbate-induced effects. In these cases, local changes in the electronic structure produced by adsorbates are reflected in local height variations in the STM image that do not correspond to the topography of adsorbed species according to their binding geometry. It has been proposed that the corrugation generally increases with decreasing adatom negativity. ${ }^{82,84}$ This conclusion has been confirmed experimentally for oxygen atoms on $\mathrm{Ni}(100) .{ }^{66,84,85}$ On the other hand, our terrace 

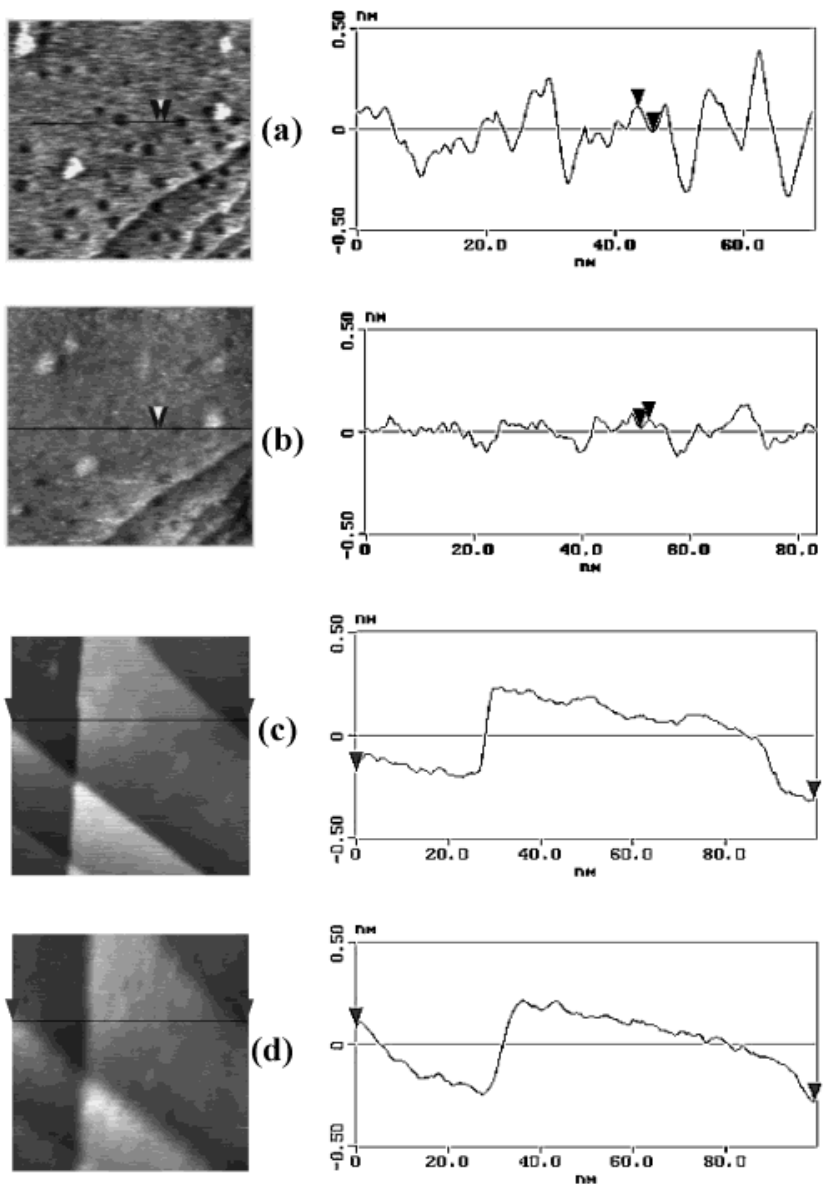

Figure 12. STM images $\left(100 \times 100 \mathrm{~nm}^{2}\right)$ showing the change in roughness of gold samples in $1 \mathrm{M}$ aqueous sulfuric acid resulting from the application of routine I. (a) Blank (rough surface). (b) Image obtained after the application of routine I up to $E_{\text {as }}=1.40 \mathrm{~V}$. (c) Blank smooth $\mathrm{Au}(111)$ surface. (d) Image resulting from the same routine up to $E_{\text {as }}=1.80 \mathrm{~V}$.

corrugation is in the range $0.035 \mathrm{~nm}$ like the theoretical corrugation profile of the oxygen atom on $\mathrm{Pd}(111) .{ }^{87}$ Accordingly, on increasing either $E_{\mathrm{as}}$ or $t_{\mathrm{ag}}$, a relatively large fraction of O-containing electroadsorbates on $\mathrm{Au}(111)$ would be preferentially located on hole position. ${ }^{88}$ This is consistent with both the multiplicity of current peaks in the electroreduction voltammograms and the number of O-containing species on anodized $\mathrm{Au}(111)$ at different $E_{\text {as }}$ resulting from the deconvolution of the O1s XPS signal. It appears that at more positive $E_{\text {as }}$ and larger $t_{\mathrm{ag}}$, most of the $\mathrm{OH} / \mathrm{O}$-species are located on hole position. ${ }^{88}$ Accordingly, the sequence of voltammetric electroreduction peak potentials for the various $\mathrm{O}$-containing adsorbates increases negatively in the order $\mathrm{OH}$ (on top) $<\mathrm{OH} / \mathrm{O}$ (on hole) $<\mathrm{O}$ (oxo-hydroxide) species.

It should be noted that the rate constant of the electron-transfer step coupled to the replacement-turnover process is in the order of $10^{3} \mathrm{~s}^{-1},{ }^{37-39}$ whereas the rate constant of the global relaxation process involving surface gold atoms and adsorbate species is estimated as $10^{-3} \mathrm{~s}^{-1}$, a figure that would depend on the solution composition and characteristics of the potential routine. Relaxation processes at the anodic layer occur spontaneously under open circuit as well as under applied potential conditions. ${ }^{37-39}$

4.4.2. The Electroreduction Stage. The electroreduction stage can be globally represented by the reverse of reactions $1-4$, although definitely the initial topography of the substrate is not recovered. Processes following the fast initial electroreduction of the oxygen-containing layer involve the displacement of gold atoms driven by chemical potential gradients at the gold surface consisting of a redistribution of steps, terraces, and other intrinsic defects, such as corners and kinks, and extrinsic defects (impurities).

The first electroreduction step would involve the 2D nucleation of gold adatoms from oxygen-containing gold clusters. This process is often found in the electrocrystallization of metals such as gold, platinum, and palladium, ${ }^{89,90}$ and can be followed through the current transients run at different constant potentials. However, the change in potential produced by routine II from at $E_{\text {as }}$ to $E=0.50 \mathrm{~V}$ involves gold atom clustering, a local accumulation of $\mathrm{OH}^{-}$at the reaction interface, and a change in gold-sulfate ion interactions leading to a disordered adsorbate layer. Then, the effect produced by routine II would be comparable to a rapid jump of the system from a quasiequilibrium situation at $E_{\text {as }}$ to a new one far from equilibrium. This effect is reflected in the spinodal structure that can be seen in the corresponding STM images (Figure 8). Then, the system at $E_{\mathrm{i}}$ would evolve to a new equilibrium by successive steps such as nucleous growth followed by the attachement of gold adatoms to growing nuclei, island-island and hole-hole coalescence phenomena, and Ostwald ripening, i.e., hole filling by particle attachment to edges. ${ }^{91}$ The common feature among these stages is the key role played by the surface diffusion of gold adatoms and clusters. It is known that the rate of surface diffusion of gold atoms on gold terraces and step edges is higher than for inter-terrace jumping because of the existence of an Erlich-Schwebel activation energy barrier, ${ }^{92}$ although the ratio among the rate of these processes depends on the atom displacement anisotropy.

Generally, a specific time scale is related to each successive step leading to equilibrium, and when the discrimination of these steps becomes possible, their kinetics can be studied independently. Usually, their corresponding rate equation is of the form rate $\approx t^{n}$, with a specific exponent $n$ usually ranging from 0.25 to $0.50 .8^{84,91,93}$ For convoluted phenomena these steps can be separated as limiting cases after the knowledge of contributing process by independent measurements becomes possible. For this particular case, the evaluation of the distribution function of islands and holes provides relevant information about the time scale related to the different phenomena.

4.4.2.1. The Gold Cluster Distribution Function. The distribution function, $f(r)$, of hemispherical gold clusters of radius $r$ on graphite has been evaluated by scanning transmission electron microscopy ${ }^{94}$ and correctly interpreted with a 3D model based on the following equation

$$
f(r)=N r^{3} \exp \left[-(r / b)^{2}\right]
$$

where $b$ is directly related to $\langle r\rangle$, the average cluster radius, and $N$ is a normalization factor. Then, it appeared reasonable to attempt to extend eq 12 to the $2 \mathrm{D}$ clusters resulting from the first stages of $\mathrm{Au}(111)$ faceting. For this purpose, let us express $f(r)$ as a distribution function, $F(n)$, of the number of particles, $n$, in the cluster, such as $n=C r^{3}, C$ being a proportionality constant. Then, the expression for $F(n)$ is

$$
F(n)=f[r(n)](\mathrm{d} r / \mathrm{d} n)=N^{\prime} n^{1 / 3} \exp \left(-\beta n^{2 / 3}\right)
$$

where $N^{\prime}$ is a new normalization factor and $\beta=1 / b^{2} C^{2 / 3}$. We proposed that eq 13 describes the distribution of both $3 \mathrm{D}$ and $2 \mathrm{D}$ clusters. Thus, to obtain the distribution of radii of $2 \mathrm{D}$ clusters, $n=K r^{2}$, eq 13 should be written in terms of $r$. The 

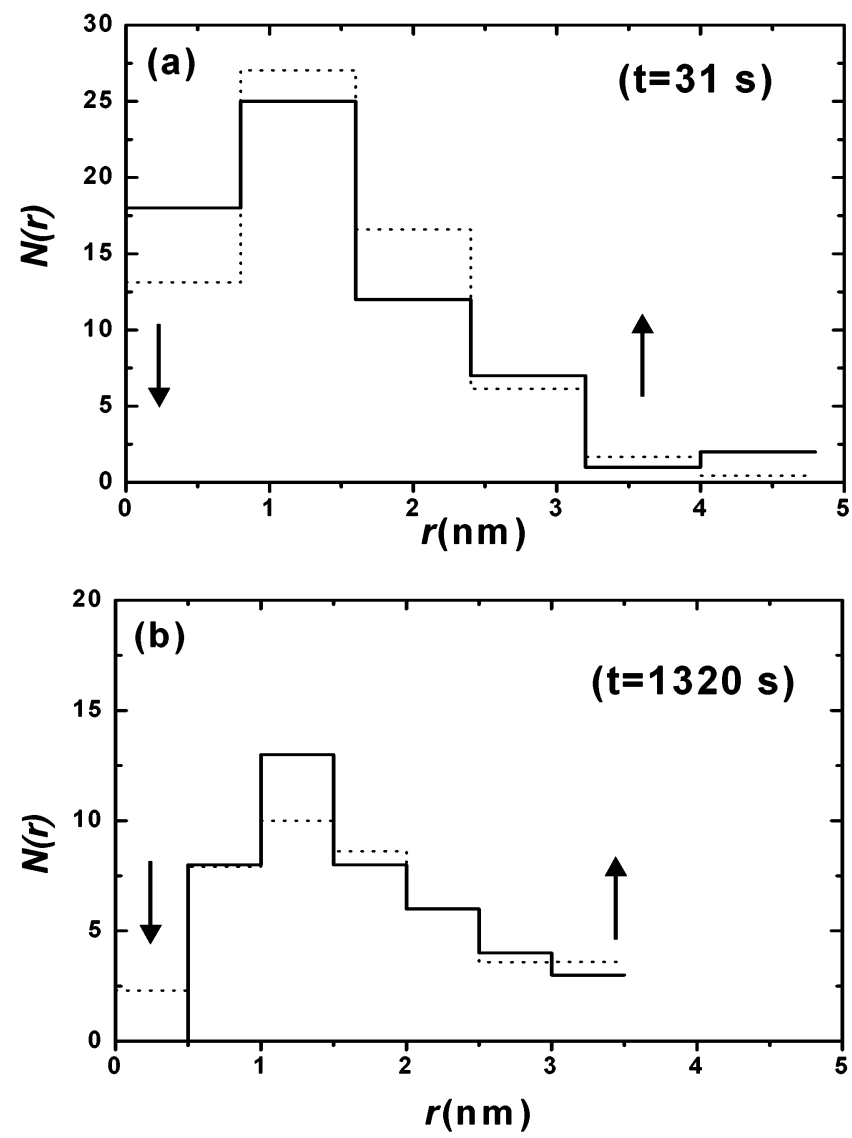

Figure 13. Size distribution function of gold clusters at constant potential $(E=0.50 \mathrm{~V})$ for $t=31 \mathrm{~s}$ and $t=1320 \mathrm{~s}$. Dotted lines correspond to the theoretical distribution functions for the short (a) and long time range (b), calculated for $\langle r\rangle=1.48 \mathrm{~nm}$ and $\langle r\rangle=1.68$ $\mathrm{nm}$, respectively. Full traces correspond to experimental data. Arrows show the decreasing and the increasing number of small and large clusters, respectively, that occur from 31 to $1320 \mathrm{~s}$.

resulting normalized single parameter equation is

$$
F(r)=(4 / 3) \alpha^{2} r^{5 / 3} \exp \left(-\alpha r^{4 / 3}\right)
$$

The parameter $\alpha$ can be expressed as a function of $r_{\mathrm{M}}$, the value of $r$ that leads to the maximum of $F(r)$ value, i.e.,

$$
\alpha=(5 / 4) r_{M}^{-4 / 3}
$$

To compare experimental data to eq $14, F(r)$ was discretized to obtain histograms with a number of counts per site appropriate for a reasonable statistics. For this purpose, the value of $\langle r\rangle$ of gold clusters measured from the STM images was taken to be equal to the value of $\langle r\rangle$ derived from the theory. Then, the relationship between $\langle r\rangle$ and $\alpha$ is

$$
\langle r\rangle=\alpha^{-3 / 4} \Gamma(11 / 4)
$$

and from eq 15 , it follows that

$$
r_{\mathrm{M}}=(5 / 4)^{3 / 4}\langle r\rangle / \Gamma(11 / 4)
$$

Thus, taking $\Gamma(11 / 4)=1.608$, the relationship between $\langle r\rangle$ and $r_{\mathrm{M}}$ results in

$$
r_{\mathrm{M}}=0.735\langle r\rangle
$$

Accordingly, for the long time range, $r_{\mathrm{M}}=1.23 \mathrm{~nm}$; for the short time range, $r_{\mathrm{M}}=1.09 \mathrm{~nm}$. Experimental data are
TABLE 3: Kinetic Relationships Derived from the Cluster Size Distribution Functions Shown in Figure 14, for Different Values of $\langle r\rangle$ at $t_{1}=31 \mathrm{~s}$ and $t_{2}=1320 \mathrm{~s}$

\begin{tabular}{lcccccc}
\hline$\langle r\rangle /$ & & & & & $N\left(r_{2}\right) /$ & $N\left(r_{2}\right) /$ \\
$\mathrm{nm}$ & $\left(t_{2} / t_{1}\right)^{1 / 3}$ & $\left(t_{2} / t_{1}\right)^{1 / 4}$ & $\left(r_{2}\right)$ & $N\left(r_{1}\right)$ & $N\left(r_{1}\right)(\exp )$ & $N\left(r_{1}\right)($ theo $)$ \\
\hline 0.75 & 3.49 & 2.55 & 17.5 & 8.0 & $2.2 \pm 0.5$ & 2.7 \\
3.50 & 3.49 & 2.55 & 3.0 & 1.2 & $2.5 \pm 0.5$ & 2.7 \\
$r_{\mathrm{M}}$ & 3.49 & 2.55 & 25 & 13 & 1.9 & 2.7
\end{tabular}

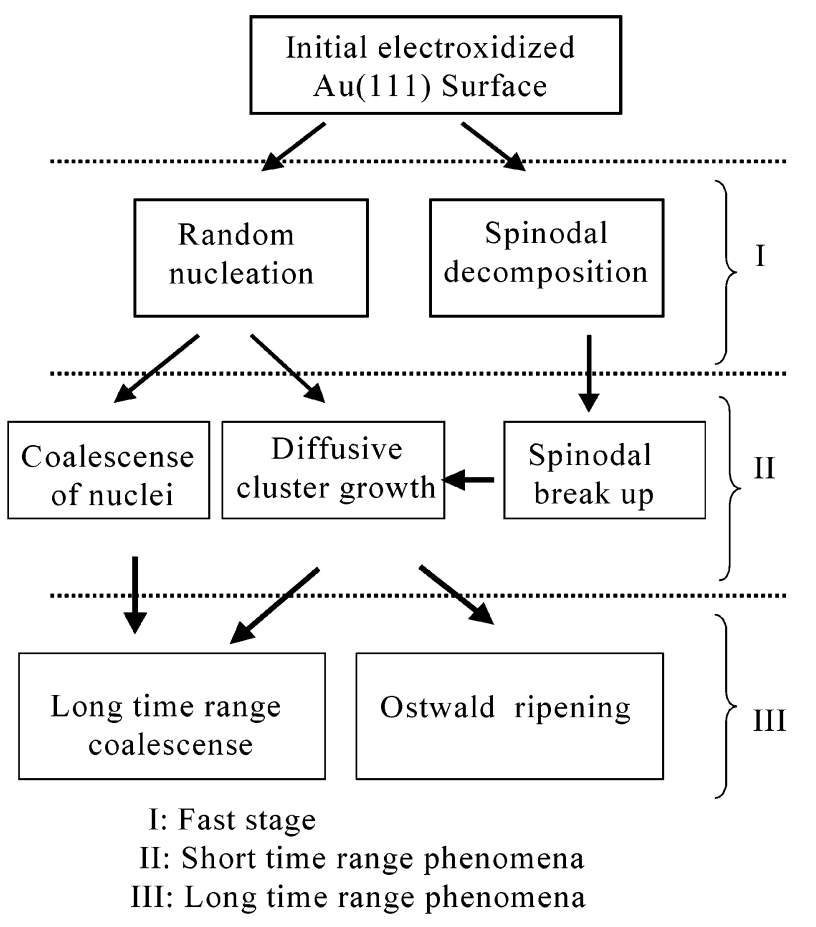

Figure 14. Scheme of the gold phase formation stages involved in the electroreduction of the oxygen-containing layers on $\mathrm{Au}(111)$ adapted from ref 91.

satisfactorily compared to the prediction of eq 14 as shown in Figure 13. For this purpose statistical methods adequate for the number of observations were considered. ${ }^{95}$

The evolution of the size distribution of clusters at constant $E$ indicates a decrease in the number of smaller clusters and an increase of larger ones in going from $t=31 \mathrm{~s}$ to $t=1320 \mathrm{~s}$. Considering a selected range of $\langle r\rangle$, one can estimate a likely value of the kinetic exponent $n$ for the relaxation processes occurring in the long time range. For this purpose, the experimental and theoretical ratios $N\left(r_{2}\right) / N\left(r_{1}\right)(\exp )$ and $N\left(r_{2}\right) /$ $N\left(r_{1}\right)$ (theo), respectively, and the ratio $\left(t_{2} / t_{1}\right)^{n}$ were evaluated to obtain the most likely value of $n$. Results are assembled in Table 3 . They confirm that for the long-term relaxation processes $n$ is close to $1 / 4$, as expected for a kinetics dominated by an unidirectional displacement of reacting species on the substrate along terrace steps, ${ }^{96,97}$ a process that for hexagonal substrates such as $\mathrm{Au}(111)$ should be constrained by anisotropic corner diffusion. ${ }^{92}$ The latter should play a key role in determining the evolution of clusters to islands with a defined geometric shape. Therefore, all these phenomena cooperate in the origin of electrochemical faceting of the $\mathrm{Au}(111)$ surface.

In conclusion, the initiation of the electrochemical faceting of $\mathrm{Au}(111)$ is to some extent comparable to the nucleation of oxygen-induced surface reconstruction that has been investigated for the $\mathrm{Au}(111)$ surface exposed to oxygen under pressure at high temperature. ${ }^{98}$ As in electrochemical faceting, the oxygeninduced restructuring of $\mathrm{Au}(111)$ leads to a periodic long-range hexagonal superstructure with a length of approximately $10 \mathrm{~nm}$ 
and a corrugation of $0.05 \mathrm{~nm}$, these figures being close to those reported in our work. This coincidence supports the initial occurrence of a cooperative nucleation and growth process that at longer times involves the participation of surface relaxation phenomena as summarized in Figure 14. In electrochemical faceting, at room temperature, kinetic data related to long-term relaxation phenomena are consistent with those data earlier derived from roughness relaxation of gold substrates. ${ }^{93,99,100}$

Acknowledgment. This work was partially supported by PICT 06-03251/98 from the National Secretariat for Science and Technology (Argentina). Dr. Felipe J. Rodríguez Nieto participates as a Research Assistant, from the Comisión de Investigaciones Científicas de la Provincia de Buenos Aires, and as a Postdoctoral Research Fellow at the Chemistry Department, Natural Sciences Faculty, University of Puerto Rico.

\section{References and Notes}

(1) Williams, E. D.; Bartelt, N. C. Ultramicroscopy 1989, 31, 36. 9, 83 .

(2) Flytzani-Stephanopoulus, M.; Schmidt, L. D. Prog. Surf. Sci. 1979

(3) Yagi, K.; Minoda, H.; Degawa, M. Surf. Sci. Rep. 2001, 43, 45.

(4) Hamelin, A. J. Electroanal. Chem. 1982, 142, 299.

(5) Ibach, H. Surf. Sci. Rep. 1997, 29, 193. 6275 .

(6) Jiang, Q.; Liang, L. H.; Zhao, D. S. J. Phys. Chem. B 2001, 195 ,

(7) Chao, F.; Costa, M. C. R. Acad. Sci. Paris, Série C 1977, 284, 765

(8) Córdova Orellana, R.; Martins, M. E.; Arvia, A. J. J. Electrochem. Soc. 1980, 127, 2628

(9) Arvia, A. J.; Canullo, J. C.; Custidiano, E.; Perdriel, C. L.; Triaca, W. E. Electrochim. Acta 1986, 31, 1359

(10) Galindo, M. C.; Perdriel, C. L.; Martins, M. E.; Arvia, A. J. Langmuir 1989, 5, 165.

(11) Herring, C. Phys. Rev. 1951, 82, 87.

(12) Canullo. J. C.; Triaca, W. E.; Arvia, A. J. J. Electroanal. Chem. 1986, 200, 397.

(13) Clavilier, J.; Chauvineau, J. J. Electroanal. Chem. 1978, 100, 461.

(14) Clavilier, J.; Armand, D.; Wu, B. L. J. Electroanal. Chem. 1982, $135,159$.

(15) Twomey, T. A. J. Electroanal. Chem. 1989, 270, 465.

(16) Honbo, H.; Sugawara, S.; Itaya, K. Anal. Chem. 1990, 62, 2424.

(17) Delahay, P. Double Layer and Electrode Kinetics; Interscience: J. Wiley: New York, 1965.

(18) Magnussen, O. M.; Hagenboeck, J.; Hotlos, J.; Behm, R. J. Faraday Discuss. 1992, 94, 329.

(19) Mirwald, S.; Pettinger, B.; Lipkowski, J. Surf. Sci. 1995, 335, 264

(20) Magnussen, O. M.; Hotlo, J.; Nichols, Kolb, D. M.; Behm, R. J. Phys. Rev. Lett. 1990, 63, 2929.

(21) Nishizawa, T.; Nakada, T.; Kinoshita, Y.; Miyashita, S.; Sazaki, G.; Komatsu, H. Surf. Sci. 1996, 367, L73.

(22) Florit, M. I.; Martins, M. E.; Arvia, A. J. J. Electroanal. Chem. 1983, 151, 209.

(23) Magnussen, O. M. Chem. Rev. 2002, 102, 679.

(24) Trevor, D. J.; Chidsey, C. E. D.; Loioacono, D. N. Phys. Rev. Lett. 1989, 62, 929 .

(25) Nichols, R. J.; Magnussen, O. M.; Hotlos, J.; Twomy, T.; Behm, R. J.; Kolb, D. M. J. Electroanal. Chem. 1990, 290, 21.

(26) Vitus, C. M.; Davenport, A. J. J. Electrochem. Soc. 1994, 141, 1291.

(27) Gao, X.; Weaver, M. J. J. Electroanal. Chem. 1994, 367, 259.

(28) Kolb, D. M.; Dakkouri, A. S.; Batina, N. In Nanoscale Probes of the Solid-Liquid Interface; NATO ASI Vol. E288; Gewirth, A. A., Sigenthaler, H., Eds.; Kluwer: Dordrecht, 1995; p 263.

(29) Schneeweiss, M. A.; Kolb, D. M.; Liu, D. Z.; Mandler, D. Can. J. Chem. 1997, 75, 1703.

(30) Schneeweiss, M. A.; Kolb, D. M. Solid State Ionics 1997, 94, 171.

(31) Jones, P. G.; Rumpel, H.; Schwarzmann, E.; Sheldrick, G. M.; Paulus, H. Acta Crystallogr. B: Struct. Crystallogr. Cryst. Chem. 1979, $35,1435$.

(32) Schwarzmann, E.; Mohn, J.; Rumpel, H. Anorg. Chem. Org. Chem. 1976, 31, 135 .

(33) He, Y.; Bourguet, E. J. Phys. Chem. B 2001, 105, 3981.

(34) Schultze, J. W.; Vetter, K. J. Ber. Bunsen-Ges. Phys. Chem. 1971, 75,470 .
(35) Dickermann, D.; Schultze, J. W. J. Electroanal. Chem. 1974, 55, 429.

(36) Conway, B. E.; Kozlowska, H. A.; Sharp, W. B. A. J. Electroanal. Chem. 1973, 43, 9.

(37) Ferro, C. M.; Calandra, A. J.; Arvia, A. J. J. Electroanal. Chem. 1974, 50,403 .

(38) Ferro, C. M.; Calandra, A. J.; Arvia, A. J. J. Electroanal. Chem. 1974, 55, 291.

(39) Ferro, C. M.; Calandra, A. J.; Arvia, A. J. J. Electroanal. Chem. 1975, 59, 239.

(40) Bruckenstein, S.; Shay, M. J. Electroanal. Chem. 1985, 188, 1131.

(41) Angerstein-Kozlowska, H.; Conway, B. E.; Hamelin, A.; Stoicoviciu, L. Electrochim. Acta 1986, 31, 1051.

(42) Angerstein-Kozlowska, H.; Conway, B. E.; Hamelin, A.; Stoicoviciu, L. J. Electroanal. Chem. 1987, 228, 429.

(43) Angerstein-Kozlowska, H.; Conway, B. E.; Tellefesen, K.; Barnett, B. Electrochim. Acta 1989, 34, 1045.

(44) Conway, B. E. Prog. Surf. Sci. 1995, 49, 531.

(45) Conway, B. E. J. Electroanal. Chem. 2002, 524/525, 4.

(46) Joudkazis, K.; Joudkazité, J.; Jodiené, T.; Lukinskas, A. J. Electroanal. Chem. 1998, 441, 19.

(47) Joudkazis, K.; Joudkazité, J.; Jasulaitiené, V.; Lukinskas, A.; Sebeka, B. Electrochem. Commun. 2000, 2, 503.

(48) Rodríguez Nieto, F.; Fachini, E.; Cabrera, C. R.; Arvia, A. J. J. Electroanal. Chem., submitted.

(49) Dakkouri, A. S.; Kolb, D. M. In Interfacial Electrochemistry; Wieckowski, A., Ed.; M. Dekker: New York, 1999; p 151.

(50) Zei, M. S.; Scherson, D.; Lehmpfuhl, G.; Kolb, D. M. J. Electroanal. Chem. 1987, 229, 99

(51) Mrozek, P.; Han, M.; Sung, Y.-E.; Wieckowski, A. Surf. Sci. 1994, $319,21$.

(52) Sung, Y.-E.; Thomas, S.; Wieckowski, A. J. Phys. Chem. 1995, 99,13513

(53) Thomas, S.; Sung, Y.-E.; Kim, H. S.; Wieckowski, A. J. Phys. Chem. 1996, 100, 11726

(54) Adzic, R. In Electrocatalysis; Lipkowski, J., Ross, P. N., Eds.; Wiley-VCH: New York, 1998; Chapter 5.

(55) Lipkowski, J.; Shi, Z.; Chen, A.; Pettinger, B.; Bilger, Ch. Electrochim. Acta 1998, 43, 2875.

(56) Kolb, D. M.; Schnider, J. Electrochim. Acta 1986, 31, 929.

(57) Wang, J.; Shi, Z.; Lipkowski, J.; Ocko, B. M.; Magnussen, O. M.;

Adzic, R. R. J. Electroanal. Chem. 1994, 376, 35.

(58) Kolb, D. M. Prog. Surf. Sci. 1996, 51, 109

(59) Sawyer, D. T. Oxygen Chemistry; Oxford University Press: London, 1991.

(60) El-Deab, M. S.; Ohsaka, T. Electrochem. Commun. 2002, 4, 288.

(61) Shingaya, Y.; Ito, M. In Interfacial Electrochemistry; Wieckowski,

A., Ed.; M. Dekker: New York, 1999; pp 287-300.

(62) Shi, Z.; Lipkowski, J. Electroanal. Chem. 1996, 403, 225.

(63) Xie, R.; Chen, D.; Wang, X.; He, T.; Liu, F.-Ch. J. Phys. Chem. B 1998, 106, 12948

(64) Uchida, H.; Ikeda, N.; Watanabe, M. J. Electroanal. Chem. 1997, 424,5 .

(65) Thomas, S.; Sung, Y.-E.; Kim, H. S.; Wieckowski, A. J. Phys. Chem. 1995, 99, 13513 .

(66) Behm, R. J. In Scanning Tunneling Microscopy and Related Methods; Behm, R. J., García, N., Rohrer, H., Eds.; Nato ASI Series, Series E, Applied Sciences; Kluwer Academic Publishers: Dordrecht-BostonLondon, 1989; Vol. 184, pp 173-209.

(67) Patrito, E. M.; Paredes Olivera, P.; Sellers, H. Surf. Sci. 1997, 380, 264.

(68) Shingaya, Y.; Ito, M. Electrochim. Acta 1998, 44, 745.

(69) Shingaya, Y.; Ito, M. J. Electrochem. Soc. 1999, 467, 299.

(70) Shingaya, Y.; Ito, M. Chem. Phys. Lett. 1996, 256, 438.

(71) Moulder, J. F.; Stickle, W. F.; Sobol, P. E.; Bomben, K. D. In Handbook of X-ray photoelectron spectroscopy; Chastain, J., Ed.; PerkinElmer Corp.: Eden Prairie, MN, 1992.

(72) Burke, L. D.; Lyons, M. E. G. In Modern Aspects of Electrochemistry; White, R. E., Bockris, J. O’M., Conway, B. E., Eds.; Plenum Press: New York, 1986; Vol. 18, p 169.

(73) Dickenson, T.; Povey, A. F.; Sherwood, P. M. A. J. Chem. Soc., Faraday Trans. 1 1975, 71, 298.

(74) Peuckert, M.; Coenen, F. P.; Bonzel, H. P. Surf. Sci. 1984, 141, 515 .

(75) Thiel, F. A.; Madey, T. E. Surf. Sci. Rep. 1987, 7, 211.

(76) Henderson, M. A. Surf. Sci. Rep. 2002, 46, 1.

(77) Handbook of Chemistry and Physics, 60th ed.; Weast, R. C., Ed.; CRC Press: Boca Raton, FL, 1980; D-167.

(78) Giesen, M.; Kolb, D. M. Surf. Sci. 2000, 468, 149.

(79) Wiechers, J.; Twomey, T.; Kolb, D. M.; Behm, R. J. J. Electroanal. Chem. 1988, 248, 451.

(80) Lei, H.-W.; Uchida, H.; Watanabe, M. Langmuir 1997, 13, 5312.

(81) He, Y.; Borguet, E. Faraday Discuss. 2002, 121, 17. 
(82) Jaklevic, R. C.; Elie, L. Phys. Rev. Lett. 1988, 60, 120.

(83) Doyen, G.; Krakova, E.; Kopatzki, E.; Behm, R. J. J. Vac. Sci. Technol. 1988, A6, 327.

(84) Pettinger, B.; Bao, X.; Wilcock, I. C.; Muhler, M.; Ertl, G. Phys. Rev. Lett. 1994, 72, 1561.

(85) P. Sautet, C. J. Phys. Rev. B 1988, 38, 12238.

(86) Lang, N. D. Comments Cond. Matter Phys. 1989, 14, 253.

(87) Kopatzki, E. Surf. Sci. 1991, 245, 255.

(88) Tilinin, I. S.; Rose, M. K.; Dunphy, J. C.; Salmeron, M.; Van Hove, M. A. Surf. Sci. 1998, 418, 511.

(89) Litsvan, Surf. Sci. 1986, 173, 377.

(90) Schmeisser, H.; Harsdorff, M. Philos. Mag. 1973, 27, 739.

(91) Zinke-Allmang, M.; Feldman, L. C.; Grabow, M. H. Surf. Sci. Rep. 1992, 16, 377 .

(92) Brune, H.; Roeder, H.; Bromann, K.; Kern. K.; Jacobsen, J.; Stolze, P.; Jacobsen. K.; Norskov, J. Surf. Sci. 1996, L115, 349.
(93) Gimeno, F.; Hernández Creus, A.; Carro, P.; González, S.; Salvarezza, R. C.; Arvia, A. J. J. Phys. Chem. B 1999, 103, 3900.

(94) Farrel, J. E.; Valls, O. T. Surf. Sci. 1988, 199, 586.

(95) Cramer, H. Mathematical Methods of Statistics; Princeton University Press: Princeton, 1996.

(96) Salvarezza, R. C.; Arvia, A. J. In Modern Aspects of Electrochemistry; Conway, B. E., Bockris, J. O’M., White, R. E., Eds.; Plenum Press: New York, 1996; Vol. 28, p 289.

(97) Arvia, A. J.; Salvarezza, R. C.; Vara, J. M. Electrochim. Acta 1992, $37,2155$.

(98) Chevrier, J.; Huang, L.; Zeppenfeld, G.; Comsa, G. Surf. Sci. 1996, 355,1 .

(99) Alonso, C.; Salvarezza, R. C.; Vara, J. M.; Arvia, A. J. Electrochim. Acta 1990, 35, 1331

(100) Martin, H.; Carro, P.; Hernández Creus, A.; González, S.; Salvarezza, R. C.; Arvia, A. J. J. Phys. Chem. B 2002, 106, 4232. 